\title{
Feature Extraction of Oscillating Flow with Vapor Condensation of Moist Air in a Sonic Nozzle
}

\author{
Hongbing Ding ${ }^{1}$, Yiming $\mathrm{Li}^{1}$, Chao Wang ${ }^{1 *}$, Chuang Wen ${ }^{2}$, Yuhe Tian ${ }^{1}$ \\ 1 Tianjin Key Laboratory of Process Measurement and Control, School of Electrical and Information \\ Engineering, Tianjin University, Tianjin 300072, China \\ 2 Faculty of Engineering, University of Nottingham, University Park, Nottingham NG7 2RD, UK
}

Corresponding author Tel.: +86022 27402023

wangchao@tju.edu.cn

\begin{abstract}
The sonic nozzle is commonly used in flow measurement. However, the non-equilibrium condensation phenomenon of moist air in the nozzle has a negative effect on the measuring accuracy. To investigate this complex phenomenon, the experiments on the oscillating condensation flow of moist air were conducted by an adjustable humidification apparatus with different relative humidity (0$100 \%)$, temperature $\left(30-50^{\circ} \mathrm{C}\right)$ and carrier gas pressure $(1-6$ bar $)$, where the micro size pressure measuring system was designed by Bergh-Tijdeman (B-T) Model. The accurate mathematical model of nonequilibrium condensation was also built and validated by the experimental data of time-averaged pressure distribution. Then, the frequency and intensity of pressure fluctuation of oscillating flow at a wide range of operation condition were obtained combining experimental data and physical simulation model. Importantly, a new semi-empirical relation of dimensionless frequency deduced from dimensionless analysis was identified accurately by experimental data. Finally, the signal nonstationarity was also observed by using the continuous wavelet transform (CWT). The instantaneous frequency saltation and the energy attenuation of pressure signals were observed in the condensation flow.
\end{abstract}

Keywords: Sonic nozzle; vapor condensation; oscillating frequency and intensity; semi-empirical relation; CWT; nonstationary

\section{INTRODUCTION}

The sonic nozzle is widely used to measure mass flow rate [1]-[2]. The discharge coefficient is a crucial performance parameter for ISO 9300 sonic nozzle which is affected by humidity (by Li [3], Lim [4], Chahine [5]), roughness (by Anthony [6], Alper [7], Wang [8]), geometry (by Park [9], Kim [10]) and vapor condensation (by Li [11], Ding [12]-[13]). The non-equilibrium condensation in sonic nozzle can result in the lower measurement accuracy, due to both steady and unsteady flow which is caused by the supercritical heat addition, namely thermal choking [14], depending on the inlet stagnation condition [15], especially subcooled temperature or humidity of the moist gas. Thus, the condensation phenomenon of moist gas in a sonic nozzle should be investigated further, in order to improve the measurement accuracy and stability of mass flow-rate.

For decades, the steady condensation of the moist gas has been investigated experimentally. Setoguchi [16] and Matsuo [17] produced a condensation flow by expanding the moist air in a supersonic nozzle with the stagnation pressure of $102 \mathrm{kPa}$ and the stagnation temperature of $287 \mathrm{~K}$. 
The static pressure distribution is acquired by moving the lower wall and the Schlieren photographs were also obtained by using an optical system. Wyslouzil [18] presented several experimental data of the humid nitrogen binary steady condensations in a supersonic nozzle. The inlet conditions were the total pressure of $0.6 \mathrm{bar}$, the total temperature of $286.7 \mathrm{~K}$, and the maximum vapor partial pressure of 0.01 bar. Lamina [19]-[20] also used compressed humid nitrogen to research the steady nucleation and droplet growth processes in the moist gas case. The inlet conditions were the total pressure of 0.913 bar, the total temperature of $283.1 \mathrm{~K}$, and the stagnation supersaturation ratio of 0.613 (Nozzle code G1 and G2). Ding [13] designed a sonic nozzle, according to ISO standard 9300, to experimentally research the condensation phenomenon of the moist gas in the inlet pressure of both 4 bar and 8 bar, and relative humidity ranging from $42 \%$ to $63 \%$ with a constant temperature.

To predict transonic flows involving a complex non-equilibrium condensation, the mathematical computational fluid dynamics (CFD) modelling is a powerful simulation tool. The mathematic modelling of this non-equilibrium condensation flow includes the nucleation and droplet growth theory [21]. Ma et al. [22]-[23] built an Eulerian multi-fluid turbulence model in moist air. Lv and Bai [24] built a model for non-equilibrium condensation in gaseous carrier flows. Ding [25] presented a gasliquid two-phase model for the moist gas condensation flow. Hamidi [26] proposed an inviscid nonequilibrium thermodynamic model. Besides, for pure steam, Bakhtar [27], Young [28], Halama [29] and Chang [30], Jabir [31], Wang [15] and Ding [32] built two or three-dimensional mathematical models for vapor condensation.

With the latent heat addition increasing to supercritical value, the flow will occur the thermal choking and probably become unsteady. Wegener [33]-[34] firstly noted that this unstable flow and proposed a semi-empirical formula for calculating the frequency of oscillating pressure. However, this formula has a maximum error of $60 \%$ when the humidity is lower than 1 and the parameters in his formula are not independent of each other. Then, Matsuo [35] observed experimentally the flow oscillation when the moist air expanded rapidly. In 1985, Frank [36] investigated experimentally the heat addition using a Laval nozzle and found that the flow becomes unsteady in the high humidity. Skillings [37] also obtained the frequency and amplitude of the oscillating pressure. In 1997, Adam [38] presented instabilities of unsteady supersonic flows of moist gas experimentally and numerically. Malek [39], Yu [40] and Ding [41] investigated the oscillation in non-equilibrium two-phase flow. However, most of researches did not provide an accurate empirical formal for oscillation frequency. In addition, there is no sufficient information for the intensity of the pressure fluctuation which is crucial for evaluating the effect of condensation on the metrology of flow rate of sonic nozzle. Thus, the characteristics of frequency and intensity of oscillating condensation flow in sonic nozzle at different inlet humidity, temperature and carrier gas pressure should be investigated further.

In the present study, the experiments on the unsteady non-equilibrium condensation flow of the moist air in a sonic nozzle were conducted by using an adjustable humidification apparatus. The accurate mathematical model of vapor condensation was built and validated by experiment result. Then the frequency and intensity of pressure fluctuation signal of self-excited oscillation were extracted combining experiment and physical simulation model. A more accurate semi-empirical formula of 
dimensionless frequency was obtained as a function of the inlet relative humidity and saturated mass fraction of water vapor. At last, the nonstationary features were also discovered by continuous wavelet transform (CWT) which increases the complexity of fluid flow.

\section{INSTABILITY AND PERIODICITY OF THE TRANSONIC CONDENSATION FLOW}

Non-equilibrium condensation phenomenon in sonic nozzle can be qualitatively described as shown in Fig 1 (a) and (b). An unsaturated water-vapor air mixture enters into the nozzle, both gas pressure and temperature drop and reach the saturation state near nozzle throat (region I in Fig 1 (b)). Owing to the absence of condensation surface, the water vapor becomes supersaturated and several condensation nuclei are formed (region II). The number is small at first and no condensation appears in this regime [42]. Then, the measurable condensation occurs at Wilson point and visible fog appears (region III). These tiny drops will continue to grow gradually along with a pressure jump which is affected by inlet humidity, temperature and carrier gas pressure. The dimensionless expression of critical heat addition $Q_{c r}$ [43] leading to the thermal choking is expressed as

$$
Q_{c r}=\frac{q_{c r}}{c_{p} T_{01}}=\left(\frac{T_{02}-T_{01}}{T_{01}}\right)_{M_{2}=1}=\frac{\left(1-M_{1}^{2}\right)^{2}}{2(1+\gamma) M_{1}^{2}\left[1+1 / 2(\gamma-1) M_{1}^{2}\right]}
$$

where $q_{c r}$ is critical heat addition, $c_{p}$ is specific heat capacity, $T$ is temperature, $M$ is Mach number, $\gamma$ is isentropic exponent and $0<Q_{c r}<1.0417$ for $1<M<\infty$. The subscript 1 and 2 denote initial and final states of control surface at heat addition region. When the heat addition is larger than critical value, the condensation will be choked and an induced shock wave might appear.

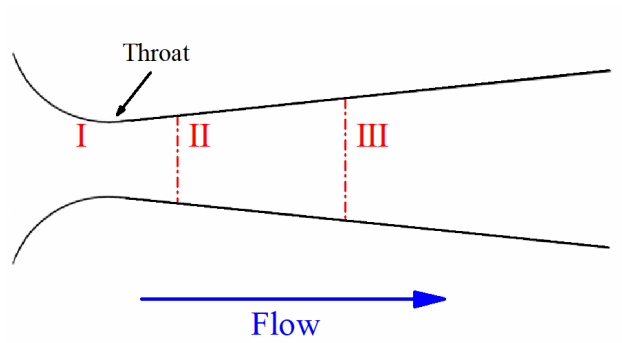

(a) Nozzle structure and condensation zones

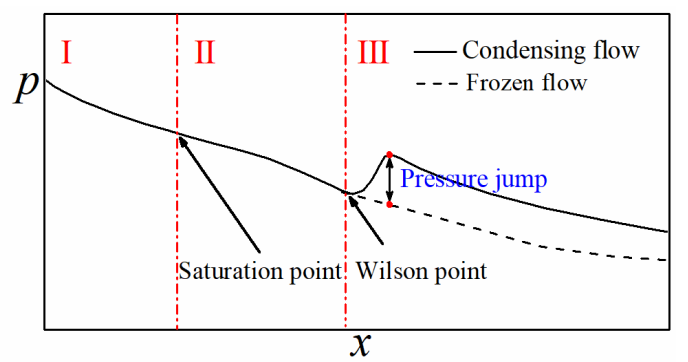

(b) Pressure changes in condensing and frozen flows

Fig 1 Typical condensation zones in sonic nozzle and pressure changes.

When the heat addition increases, the flow will not be steady and there will occur periodic selfexcited oscillation with a particular frequency and intensity. The unsteady flow frequency of condensation $f^{0}$ for a two dimensional nozzle was gained by Wegner [33] with a semi-empirical equation, as follows,

$$
f^{0}=\frac{f l}{a_{c r}}=4.007 \Phi_{0} w_{0}^{0.53}\left(\text { error }=60 \% \text { when } \Phi_{0} \leq 100 \%\right)
$$

where $f$ is the frequency of pressure fluctuation of self-excited oscillation, $\Phi_{0}$ is the relative humidity, $w_{0}$ is the mass fraction of water vapor, $l$ is the characteristic length, and $a_{\mathrm{cr}}$ is the critical sound speed. However, when $\Phi_{0} \leq 100 \%$, it is difficult to obtain the frequency of flow oscillation accurately from Eq. 
(2) of which the calculating error will reach $60 \%$. What's worse, the intensity of pressure oscillation which implies the tendency of condensing process is not provided in Eq. (2).

\section{EXPERIMENTAL FACILITY}

\section{A. Adjustable Humidification Apparatus}

The experiments were conducted based on an adjustable humidification apparatus, as shown in Fig 2 (a) and (b), by which the inlet humidity, temperature and carrier gas pressure are adjusted synchronously. The compressed air is filtered and purified by degreaser and dryer. Then the pure air is stored in the gas holder. The gas pressure is controlled by the electric control valve from 1 bar to 6 bar. The temperature is adjusted by a tubular pipe heater. For controlling the relative humidity, the micrometer droplets are generated by the high-pressure micro-fog generator, in which the liquid flowrate $\left(Q_{\mathrm{mL}}=0-17 \mathrm{~L} / \mathrm{h}\right)$ and the droplet size (maximum diameter of $\left.50 \mu \mathrm{m}\right)$ are adjusted by the hydraulic diaphragm metering pump (HDMP) and high-pressure (HP, $P_{L}=0-12.4 \mathrm{MPa}$ ) microsprayer nozzle. Then the small droplets mix with the heated gas flow in the evaporator and then completely evaporate into the moist air which can ensure no droplet exists at the upstream of the nozzle. The humidity and temperature of the moist air can be accurately controlled in the range of $0-100 \%$ and 30$50{ }^{\circ} \mathrm{C}$ respectively. A 3D toroidal-throat sonic nozzle of which the throat diameter is $10 \mathrm{~mm}$ and curvature radius is $870 \mathrm{~mm}$ was designed, as plotted in Fig 2 (b). The measurement instruments used in the adjustable humidification apparatus are shown in Table 1.
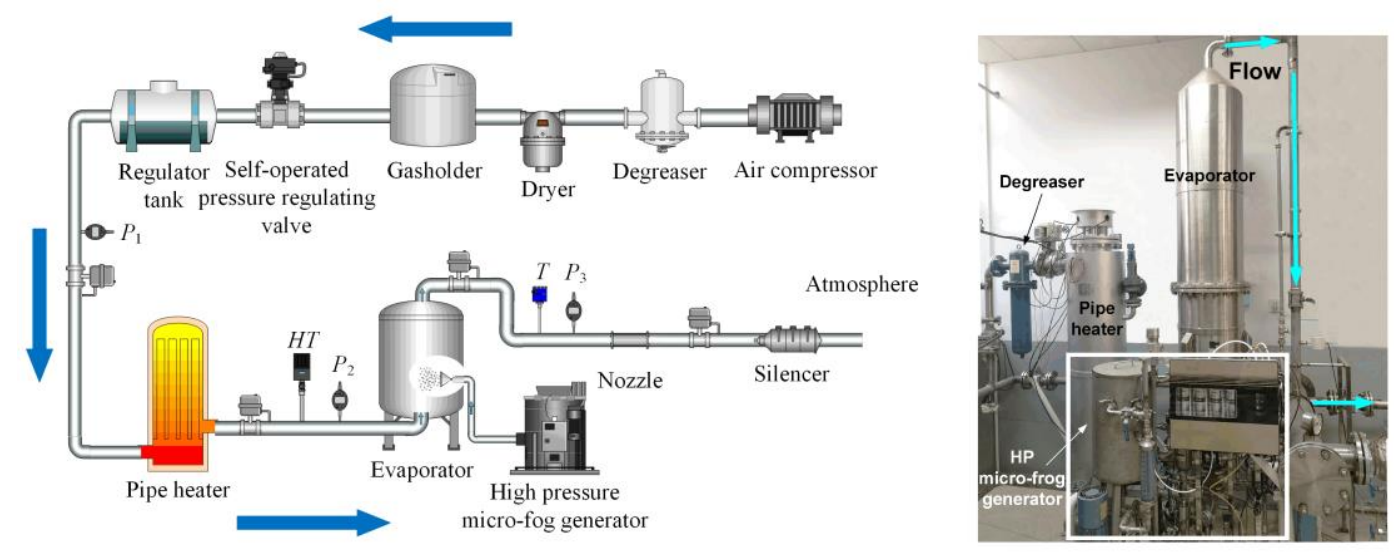

(a) Schematic and photograph of the apparatus.

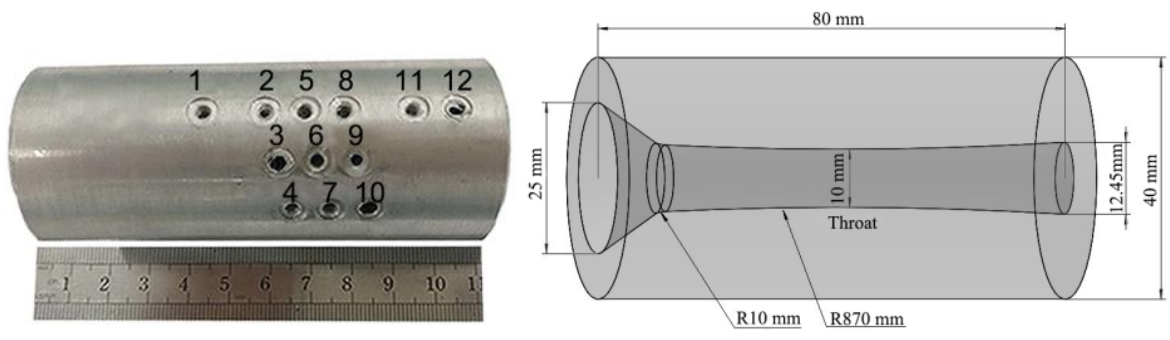

(b) The 3D toroidal-throat sonic nozzle.

Fig 2 The adjustable humidification apparatus. 
Table 1 Instruments used for measurements in the adjustable humidification apparatus

\begin{tabular}{cccc}
\hline Name & Function & Measurement range & Accuracy \\
\hline H-110 hygrometer & Measuring the & $-40{ }^{\circ} \mathrm{C}$ to $80^{\circ} \mathrm{C} ; 0 \%-100 \% \mathrm{RH}$ & $\begin{array}{c}\text { Temperature: } 0.2^{\circ} \mathrm{C} ; \\
\text { relative humidity: } 1.5 \%\end{array}$ \\
$\begin{array}{c}\text { Kulite MEMS quickly } \\
\text { response pressure sensor } \\
\text { Pt100 resistance } \\
\text { thermometer }\end{array}$ & Measuring transient & $0-8 \mathrm{bar}$ & $0.2 \%$ \\
pressure & Temperature sensor & $-150^{\circ} \mathrm{C}$ to $400^{\circ} \mathrm{C}$ & $\pm(0.15+0.002|\mathrm{t}|)^{\circ} \mathrm{C}$ \\
metering pump & Flow rate controller & & $0.32 \%$ \\
Hollow cone nozzle & Generating micrometer & Pressure: $40-100 \mathrm{bar} ; \mathrm{volume}$ & \\
& droplets & flow rate: $1.02-2.46 \mathrm{~L} / \mathrm{h}$ & - \\
Impaction-pin nozzle & Generating micrometer & Pressure: $10-70 \mathrm{bar}$ volume & \\
& droplets & flow rate: $3.3-8.7 \mathrm{~L} / \mathrm{h}$ & - \\
\hline
\end{tabular}

\section{B. Micro-size Pressure Measuring System}

Time-averaged pressure signals along the axis of nozzle and the pressure fluctuation signals at a specific point near nozzle wall are measured by using the pressure probes. The accuracy is $0.2 \%$ and the pressure range is $0-8$ bar. For the installation of the pressure probes, there are 12 holes drilled in nozzle wall of which the diameter are only $1.0 \mathrm{~mm}$ and they are numbered 1-12 respectively, as shown in Fig 2 (b). The locations of holes are shown in Table 2, where $x=0 \mathrm{~mm}$ is the location of throat. The pressure probe array consisting of 12 pressure probes are used to measure time-averaged pressure values at different positions, as shown in Fig 3 (a).

Table 2 The hole locations in nozzle.

\begin{tabular}{cccccccccccccc}
\hline Location & 1 & 2 & 3 & Throat & 4 & 5 & 6 & 7 & 8 & 9 & 10 & 11 & 12 \\
\hline$x(\mathrm{~mm})$ & -12.9 & -2.1 & -0.3 & 0.0 & 1.3 & 3.8 & 8.0 & 10.9 & 13.5 & 16.3 & 19.0 & 26.9 & 35.0 \\
\hline
\end{tabular}

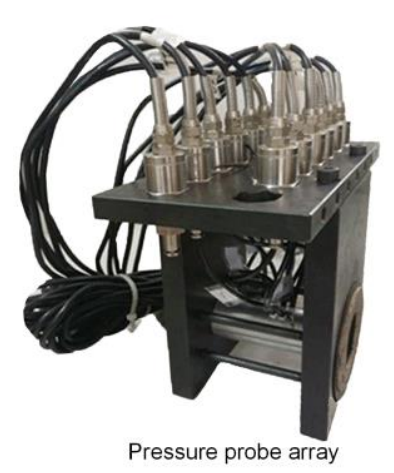

(a) Pressure probe array

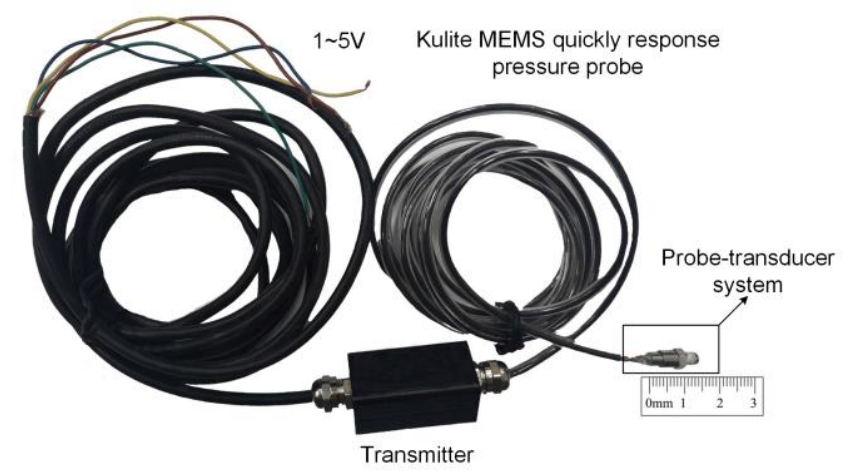

(b) Kulite MEMS quickly response pressure probe

Fig 3 The micro-size pressure measuring system.

Pressure fluctuation signals are measured at position of No.10 where the condensation intensity is the strongest in the most cases [13]. According to Eq. (2), the frequency range of self-excited 
oscillation in this experiment is estimated to be $1336-3774 \mathrm{~Hz}$. To measure this high frequency pressure accurately, it is necessary to consider the frequency response characteristic of the pressure measuring system. Limited by the space and also to minimize the disturbance to flow field, a microsize pressure probe should be designed optimally in this experiment. However, a small diameter probe has adverse effect on the frequency band of the pressure measuring system. Thus, in order to balance the relationship of them and improve the amplitude-frequency characteristic, the model of pressure measuring system is analyzed firstly.

A pressure measuring system consisting of a probe, a cavity and a pressure sensor is shown in Fig 4, where $r, l$ and $V$ are the radium and length of the probe, and the volume of the cavity respectively. One end of the probe is inserted in the flow field and the other end is contacted to the pressure sensor, $p_{i}$ and $p_{o}$ are the actual and measured pressure values, respectively. The frequency response characteristic of the pressure measuring system is calculated by Eq. (3) from B-T Model [44].

$$
\frac{p_{o}}{p_{i}}=\left[\cosh (\phi l)+\frac{V}{V_{t}}\left(\sigma+\frac{1}{k}\right) n \phi l \sinh (\phi l)\right]^{-1}
$$

where $V_{t}=\pi r^{2} l$ is the probe volume; $k$ is polytropic constant for the volumes; $\sigma$ is dimensionless increase in transducer volume due to diaphragm deflection; $n$ and $\phi$ are expressed respectively as follows,

$$
\begin{gathered}
n=\left[1+\frac{\gamma-1}{\gamma} \frac{J_{2}(\alpha \sqrt{\mathrm{Pr}})}{J_{0}(\alpha \sqrt{\mathrm{Pr}})}\right]^{-1} \\
\phi=\frac{\omega}{a_{0}} \sqrt{\frac{J_{0}(\alpha)}{J_{2}(\alpha)}} \sqrt{\frac{\gamma}{n}}
\end{gathered}
$$

where $\gamma$ is specific heat ratio; $J_{0}$ and $J_{2}$ are Bessel function of first kind of order 0 and 2; $\alpha$ is shear wave number, a measure of the wall shearing effects; Pr is Prandtl number; $\omega$ is angular frequency and $a_{0}$ is the mean velocity of sound.

$$
\begin{gathered}
a_{0}=\sqrt{\frac{\gamma p_{s}}{\rho_{s}}} \\
\alpha=i \sqrt{i r} \sqrt{\frac{\rho_{s} \omega}{\mu}}
\end{gathered}
$$

where $p_{s}$ is mean pressure, $\rho_{s}$ is mean density, $\mu$ is absolute fluid viscosity and $i$ is imaginary unit.

According to B-T Model, the pressure measuring system is designed to be $r=0.5 \mathrm{~mm}, l=11 \mathrm{~mm}$ and $V=3.98 \mathrm{~mm}^{3}$. The amplitude-frequency characteristic curve obtained is shown in Fig 5 . It is shown that the cutoff frequency (where amplitude ratio drops to $-3 \mathrm{~dB}$ ) is $7337 \mathrm{~Hz}$ and larger than the maximum estimated frequency. Thus, the designed pressure measuring system meets the measurement requirement. The Kulite MEMS quickly response pressure sensor with accuracy of $0.2 \%$ is applied to measure the pressure fluctuation signals, as shown in Fig 3 (b). 


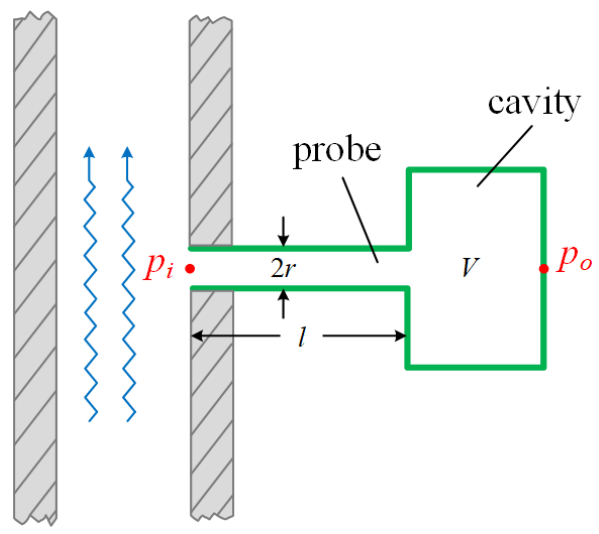

Fig 4 Structure of the pressure measuring system.

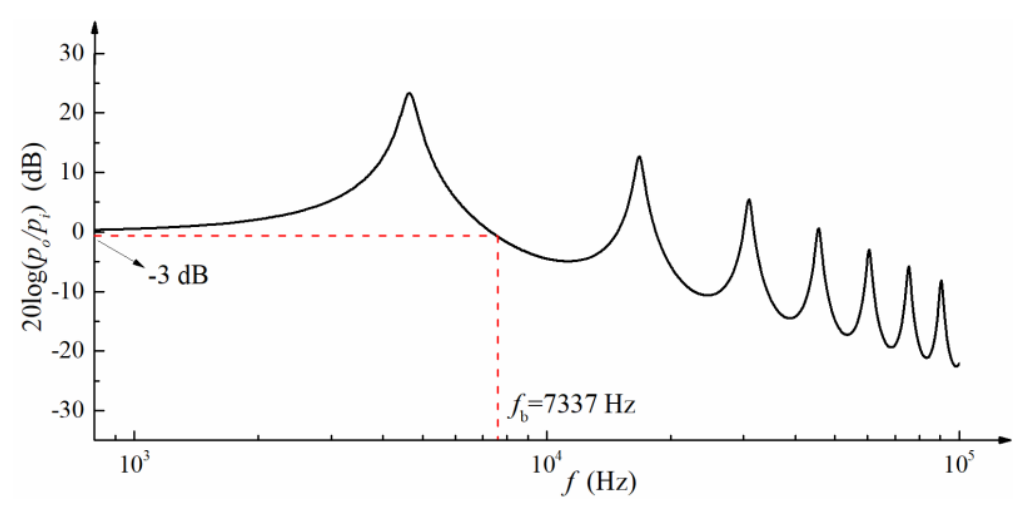

Fig 5 The amplitude-frequency characteristic curve of pressure measuring system.

The raw signal was magnified by a voltage amplifier and processed by $10^{\text {th }}$ order low-pass filter for the purpose of anti-interference, of which the cut-off frequency is $10 \mathrm{kHz}$. The pressure signals were sampled by NI-USB-6251 and LabVIEW. The sampling rate can be $1.25 \mathrm{MS} / \mathrm{s}$ for single channel and the average rate can be $1.00 \mathrm{MS} / \mathrm{s}$ for multiple channels. The sampling frequency is $40 \mathrm{kHz}$.

IV. ANALYSIS OF RESULTS

\section{A. Signal Processing Method}

The time-averaged distribution and fluctuation information of the pressure are analyzed from several raw signals. For time-averaged distribution, the pressure signal obtained from the pressure measuring system is filtered and averaged in a period of time. Then the time-averaged pressure is used to obtain the pressure distribution along the axis of nozzle and validate the mathematical model during the non-equilibrium condensation process under different humidity, temperature and carrier gas pressure conditions.

The pressure fluctuation information is obtained from the unstable pressure data at the strongest condensation position No. 10. The dominant frequency is calculated in frequency domain using power spectral density (PSD) [45]. For $t \in[-T / 2, T / 2]$, the FFT of signal $p(t)$ is $P_{T}(f)$. PSD is calculated by 


$$
\mathrm{PSD}=\lim _{T \rightarrow \infty} \frac{\left|F_{T}(f)\right|^{2}}{T}
$$

where the dominant frequency is obtained according to the spectrum line with the maximum amplitude. According to Parseval's theorem, the energy of a signal in time domain is equal to that in frequency domain. And the variance of $P(t)$ can be given by the integral of the PSD against frequency. Thus, the pressure fluctuation intensity PF from frequency $f_{1}$ to $f_{2}$ is

$$
\mathrm{PF}=\sigma=\sqrt{\frac{1}{n} \sum_{i=1}^{n}\left(p_{i}-\bar{p}\right)^{2}}=\sqrt{\int_{f_{1}}^{f_{2}} \mathrm{PSD} d f}
$$

where $\sigma$ is the standard deviation of the $p(t), p_{i}$ is the $i^{\text {th }}$ pressure value and $\bar{p}$ is the mean value. It reflects the energy of pressure fluctuation. The frequency and PF are calculated under different conditions of humidity, temperature and carrier gas pressure.

Considering the pressure fluctuation signal is often nonstationary and wavelet analysis is effective for the modulated and complex signal, it is analyzed based on wavelet method.

Wavelet transform can be categorized as CWT and discrete wavelet transform (DWT) [46]. The CWT of a signal $f(t)$ is

$$
W f(a, b)=\frac{1}{\sqrt{a}} \int_{-\infty}^{+\infty} f(t) \psi\left(\overline{\frac{t-b}{a}}\right) d t
$$

where $\psi(t) \in L^{2}(R)$ is the mother wavelet; $a$ is the scale factor; $b$ is the time shifting factor. The DWT is used by discretizing $a$ and $b[47]$ in terms of a power series.

By using DWT, pressure fluctuation signals are decomposed into different frequency components. The parameter, flatness (FF) [48]-[49] of each component, which can measure the sharpness of the distribution and can be used as a measure of intermittency, is calculated by

$$
\mathrm{FF}=\frac{1}{n \sigma^{4}} \sum_{i=1}^{n}\left(p_{i}-\bar{p}\right)^{4}
$$

To investigate the nonstationary signal in detail, CWT is used to obtain the characteristic in timefrequency domain. Generally, the wavelet coefficient can be transformed to the local wavelet energy (LWE) coefficient $W L$ by Eq. (12).

$$
W L=\frac{\left|W f^{2}\right|}{a}
$$

It can enhance the energy of each frequency component while the scale characteristic of the wavelet coefficients remains unchanged [46]. To quantitatively represent the instantaneous frequency and its intensity, wavelet ridge [50]-[51] is extracted from LWE coefficient based on modulus maxima.

\section{B. Mathematical Model Validated by Time-averaged Pressure Distribution}

At present, the mathematical CFD model provides attractive features for analyzing this unsteady nonequilibrium condensation with low cost compared to experiment. For the purpose of properly 
assessing the uncertainty of a mathematical model, it must be validated by sufficient experiments. As we know, in this mathematical model, the critical radius of droplet $r^{*}$ is calculated by $r^{*}=2 \sigma /\left(\rho_{d} \Delta G_{1}\right)$, where $\rho_{d}$ is the density of dispersed phases, $\Delta G_{1}$ is bulk Gibbs free energy change and $\sigma$ is surface tension, a sensitive parameter that should be corrected by the nucleation bulk tension factor NBTF ( $\sigma=\sigma_{b u l k} \times \mathrm{NBTF}$ ) [43]. In this model, the value of the NBTF is set as 1.02 determined by experimental validation with accuracy of $2.0 \%$. The details of this mathematical model can be found in Ref [52].

The experimental time-averaged pressure distribution under different conditions of inlet humidity $\Phi_{0}$, temperature $T_{0}$ and carrier gas pressure $P_{0}$ are illustrated in Fig 6 (a) and (c), Fig 7 and Fig 8, where $P / P_{0}$ is the ratio of measured time-averaged pressure and inlet stagnation pressure. Meantime, the physical simulation results at the same conditions are also plotted in the figures. In addition, the latent heat addition rate under different $\Phi_{0}$ is shown in Fig 6 (b) and (d). The results show that the experimental results are well consistent with the physical simulation data and the pressure jump can be captured accurately.

In the conditions of $P_{0}=300 \mathrm{kPa}, T_{0}=50^{\circ} \mathrm{C}$ and $P_{0}=400 \mathrm{kPa}, T_{0}=50^{\circ} \mathrm{C}$ respectively, Fig 6 (a) and (c) show that with the increasing of $\Phi_{0}$, the position of the pressure jump moves upstream and the pressure value increases. The onset point occurs at the downstream of the throat at first and then moves upstream. It means that the change of humidity has obvious effect on the condensation position and intensity. As the relative humidity is increased, the condensation is more likely to occur and the onset point occurs earlier in the nozzle with stronger intensity. Accordingly, as shown in Fig 6 (b) and (d), at low relatively humidity, the latent heat addition rate $q_{l}$ is small. With $\Phi_{0}$ increasing, the release position of latent heat moves upstream at first which is consistent with the onset point, which means that the condensation is accompanied by the release of latent heat.

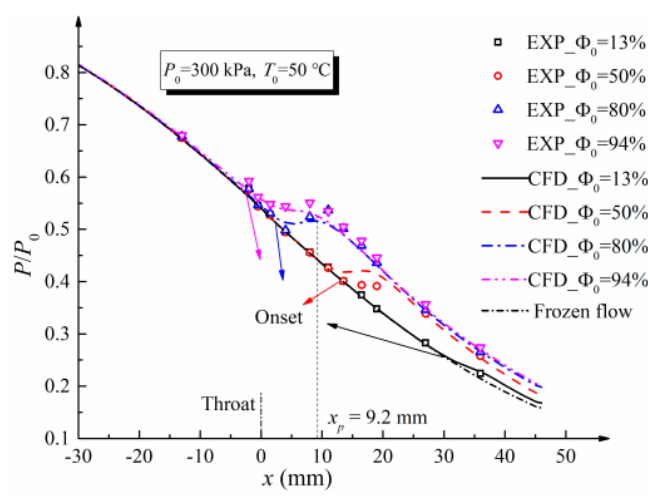

(a) $P / P_{0}$ with $P_{0}=300 \mathrm{kPa}, T_{0}=50^{\circ} \mathrm{C}$.

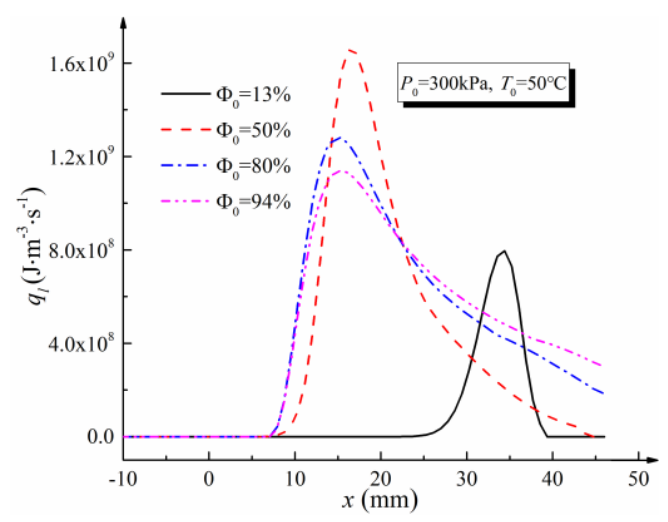

(b) $q_{l}$ with $P_{0}=300 \mathrm{kPa}, T_{0}=50^{\circ} \mathrm{C}$. 


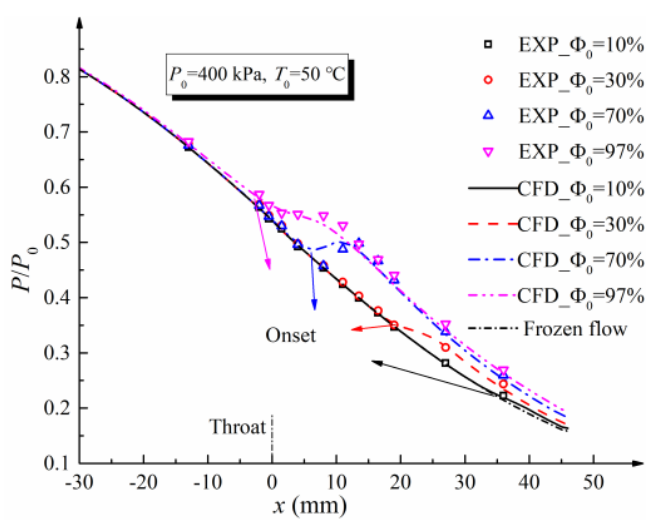

(c) $P / P_{0}$ with $P_{0}=400 \mathrm{kPa}, T_{0}=50^{\circ} \mathrm{C}$.

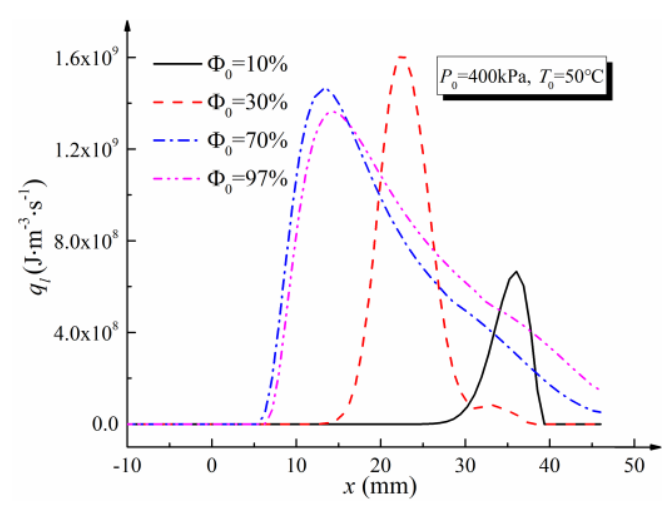

(d) $q_{l}$ with $P_{0}=400 \mathrm{kPa}, T_{0}=50^{\circ} \mathrm{C}$.

Fig 6 Pressure distribution and latent heat addition rate with humidity changing.

The condensation gets strong as the temperature increases as shown in Fig 7. The experiment conditions are $P_{0}=300 \mathrm{kPa}, \Phi_{0}=80 \%$ and $P_{0}=500 \mathrm{kPa}, \Phi_{0}=80 \%$. With the increase of temperature, the position changes slightly which means the effect of temperature on condensation position is less than humidity.

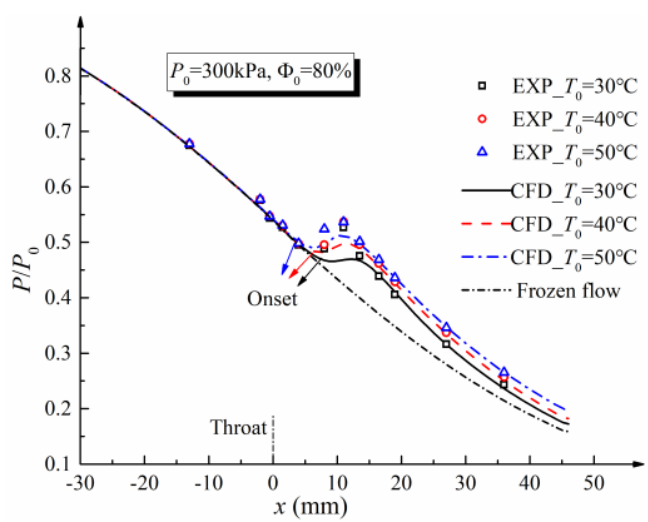

(a) with $P_{0}=300 \mathrm{kPa}, \Phi_{0}=80 \%$.

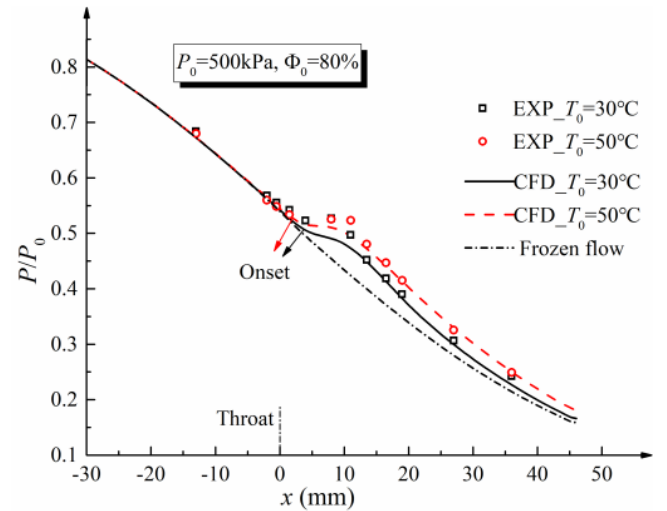

(b) with $P_{0}=500 \mathrm{kPa}, \Phi_{0}=80 \%$.

Fig 7 Pressure distribution with temperature changing.

As shown in Fig 8, with the increase of carrier gas pressure $\left(T_{0}=50{ }^{\circ} \mathrm{C}, \Phi_{0}=80 \%\right.$ and $T_{0}=30{ }^{\circ} \mathrm{C}$, $\Phi_{0}=89 \%$ ), the position of pressure jump moves upstream while the relative intensity (the change of the pressure ratio) becomes weak. The reason is that the increase of carrier gas pressure makes the change of the pressure ratio decreases.

In a word, the position of condensation moves upstream with $\Phi_{0}, T_{0}$ and $P_{0}$ increasing. And the increase of $\Phi_{0}$ and $T_{0}$ enhance the relative intensity of the condensation, but the increase of $P_{0}$ reduces it. Additionally, according to Fig 6 (a) and (c), Fig 7 and Fig 8, the condensation onset closest to the inlet is at $x=-2.6 \mathrm{~mm}$ with $P_{0}=400 \mathrm{kPa}, T_{0}=50^{\circ} \mathrm{C}$ and $\Phi_{0}=97 \%$. 


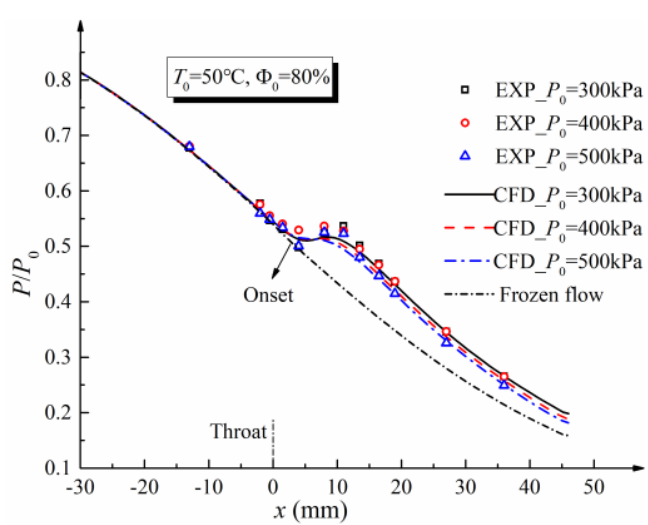

(a) with $T_{0}=50^{\circ} \mathrm{C}, \Phi_{0}=80 \%$

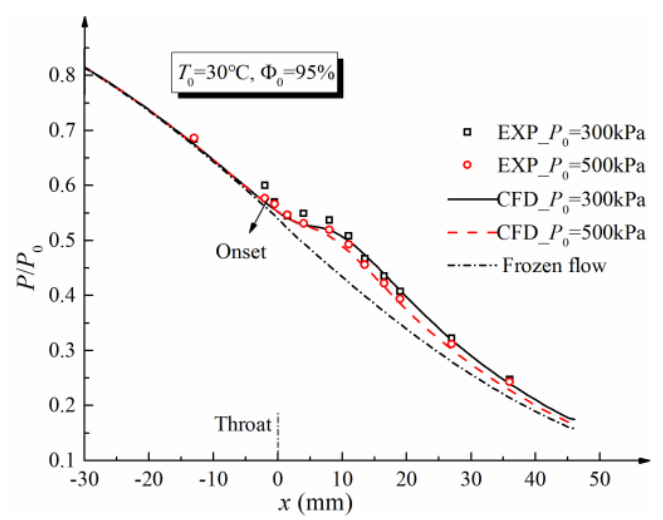

(b) with $T_{0}=30^{\circ} \mathrm{C}, \Phi_{0}=95 \%$

Fig 8 Pressure distribution with pressure changing.

As shown in Fig 1, there is a pressure jump during condensation process. Corresponding to Fig 6, Fig 7 and Fig 8, the position $x_{p}$ of pressure jump, as shown in Fig 6 (a) and its quantity $\Delta P_{j}$ which is the pressure increment comparing to the pressure of frozen flow at the same time are listed in Table 3. It shows that the maximum pressure jump quantity is $35.5 \mathrm{kPa}$ at $x=10.2 \mathrm{~mm}$ with $P_{0}=500 \mathrm{kPa}, T_{0}=$ $50^{\circ} \mathrm{C}$ and $\Phi_{0}=80 \%$.

Table 3 Pressure jump position $x_{p}$ and quantity $\Delta P_{j}$ under different conditions.

\begin{tabular}{|c|c|c|c|c|c|c|c|c|}
\hline \multirow[b]{2}{*}{$\Phi_{0}$} & \multicolumn{4}{|c|}{$P_{0}=300 \mathrm{kPa}, T_{0}=50^{\circ} \mathrm{C}$} & \multicolumn{4}{|c|}{$P_{0}=400 \mathrm{kPa}, T_{0}=50^{\circ} \mathrm{C}$} \\
\hline & $13 \%$ & $50 \%$ & $80 \%$ & $94 \%$ & $10 \%$ & $30 \%$ & $70 \%$ & $97 \%$ \\
\hline$x_{p}$ & $35.8 \mathrm{~mm}$ & $18.6 \mathrm{~mm}$ & $10.3 \mathrm{~mm}$ & $9.2 \mathrm{~mm}$ & $36.0 \mathrm{~mm}$ & $24.0 \mathrm{~mm}$ & $10.7 \mathrm{~mm}$ & $7.6 \mathrm{~mm}$ \\
\hline \multirow[t]{2}{*}{$\Delta P_{j}$} & $4.1 \mathrm{kPa}$ & $19.7 \mathrm{kPa}$ & $24.6 \mathrm{kPa}$ & $25.0 \mathrm{kPa}$ & $2.2 \mathrm{kPa}$ & $10.2 \mathrm{kPa}$ & $30.2 \mathrm{kPa}$ & $31.4 \mathrm{kPa}$ \\
\hline & \multicolumn{4}{|c|}{$P_{0}=300 \mathrm{kPa}, \Phi_{0}=80 \%$} & \multicolumn{4}{|c|}{$P_{0}=500 \mathrm{kPa}, \Phi_{0}=80 \%$} \\
\hline$T_{0}$ & $30{ }^{\circ} \mathrm{C}$ & \multicolumn{2}{|l|}{$40^{\circ} \mathrm{C}$} & $50{ }^{\circ} \mathrm{C}$ & \multicolumn{2}{|c|}{$30{ }^{\circ} \mathrm{C}$} & \multicolumn{2}{|c|}{$50{ }^{\circ} \mathrm{C}$} \\
\hline$x_{p}$ & $12.8 \mathrm{~mm}$ & \multicolumn{2}{|l|}{$12.7 \mathrm{~mm}$} & $10.9 \mathrm{~mm}$ & \multicolumn{2}{|c|}{$10.2 \mathrm{~mm}$} & \multicolumn{2}{|c|}{$9.6 \mathrm{~mm}$} \\
\hline \multirow[t]{2}{*}{$\Delta P_{j}$} & $18.2 \mathrm{kPa}$ & \multicolumn{2}{|l|}{$26.3 \mathrm{kPa}$} & $25.8 \mathrm{kPa}$ & \multicolumn{2}{|c|}{$35.5 \mathrm{kPa}$} & \multicolumn{2}{|c|}{$22.3 \mathrm{kPa}$} \\
\hline & \multicolumn{4}{|c|}{$T_{0}=50^{\circ} \mathrm{C}, \Phi_{0}=80 \%$} & \multicolumn{4}{|c|}{$T_{0}=30^{\circ} \mathrm{C}, \Phi_{0}=95 \%$} \\
\hline$P_{0}$ & $300 \mathrm{kPa}$ & \multicolumn{2}{|l|}{$400 \mathrm{kPa}$} & $500 \mathrm{kPa}$ & \multicolumn{2}{|c|}{$300 \mathrm{kPa}$} & \multicolumn{2}{|c|}{$500 \mathrm{kPa}$} \\
\hline$x_{p}$ & $10.0 \mathrm{~mm}$ & \multicolumn{2}{|l|}{$10.0 \mathrm{~mm}$} & $10.0 \mathrm{~mm}$ & \multicolumn{2}{|c|}{$8.1 \mathrm{~mm}$} & \multicolumn{2}{|c|}{$8.1 \mathrm{~mm}$} \\
\hline$\Delta P_{j}$ & $33.2 \mathrm{kPa}$ & \multicolumn{2}{|l|}{$34.5 \mathrm{kPa}$} & $27.5 \mathrm{kPa}$ & \multicolumn{2}{|c|}{$26.3 \mathrm{kPa}$} & \multicolumn{2}{|c|}{$19.9 \mathrm{kPa}$} \\
\hline
\end{tabular}

From the above results in Fig 6, Fig 7 and Fig 8, it can be seen that the NBTF value of 1.02 is appropriate for present mathematical model, which can ensure the adaptability of the model. Thus, the present model is accurate enough to apply to the further research of pressure fluctuation.

\section{Feature Extraction and Semi-empirical Relation for Pressure Fluctuation}

The frequency and intensity information are extracted and analyzed in detail. First of all, the signal is filtered by DWT. In order to calculate the DWT coefficients, Daubechies 4 was chosen as the mother wavelet and an 8-level DWT was carried out on the raw signal. According to the estimated 
frequency range of the signal, D3 $(2500-5000 \mathrm{~Hz})$ and D4 $(1250-2500 \mathrm{~Hz})$ were chosen to be reconstructed.

The filtered signal in time and frequency domain are in Fig 9. Calculated by Eq. (8) and (9), the main frequency is $2705 \mathrm{~Hz}$ where the power spectrum $P_{f}$ is $0.17 \mathrm{~W} / \mathrm{Hz}$, as shown in Fig 9 (b).

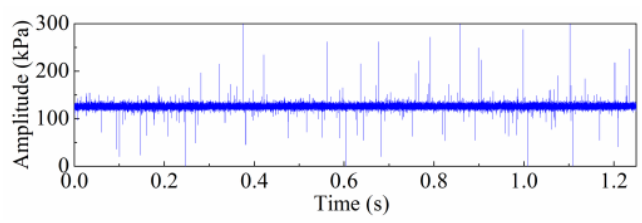

(a) Signal in time domain

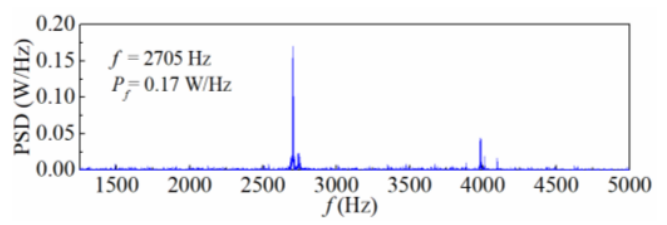

(b) Signal in frequency domain

Fig 9 Signal in time and frequency domain.

The frequency and intensity of pressure fluctuation signals are calculated and shown in Fig 10 Fig 12. The results of experiment and mathematical model are also compared. It can be seen that this physical simulation model has an excellent predictive perform. The fitted curves in these figures also show the change tendency of frequency and intensity of pressure fluctuation.

For $P_{0}=250 \mathrm{kPa}$ and $T_{0}=30^{\circ} \mathrm{C}$, Fig 10 shows that the frequency increases with $\Phi_{0}$ increasing, which is corresponding to Eq. (2). The unsteady flow occurs at $\Phi_{0} \geq 60 \%$. Then, along with $\Phi_{0}$ increasing, the intensity PF will increase rapidly at first and then start to go down generally. That is because the condensation is more likely to occur and the position moves upstream with humidity increasing. The larger released latent heat and lower critical heat addition jointly result in stronger oscillating state; thus, the frequency of self-excited oscillation is higher. In higher humidity, the oscillating condensation shock moves from divergent section to the convergent section, the supersaturation at condensation region becomes weak leading to oscillation intensity decreasing.

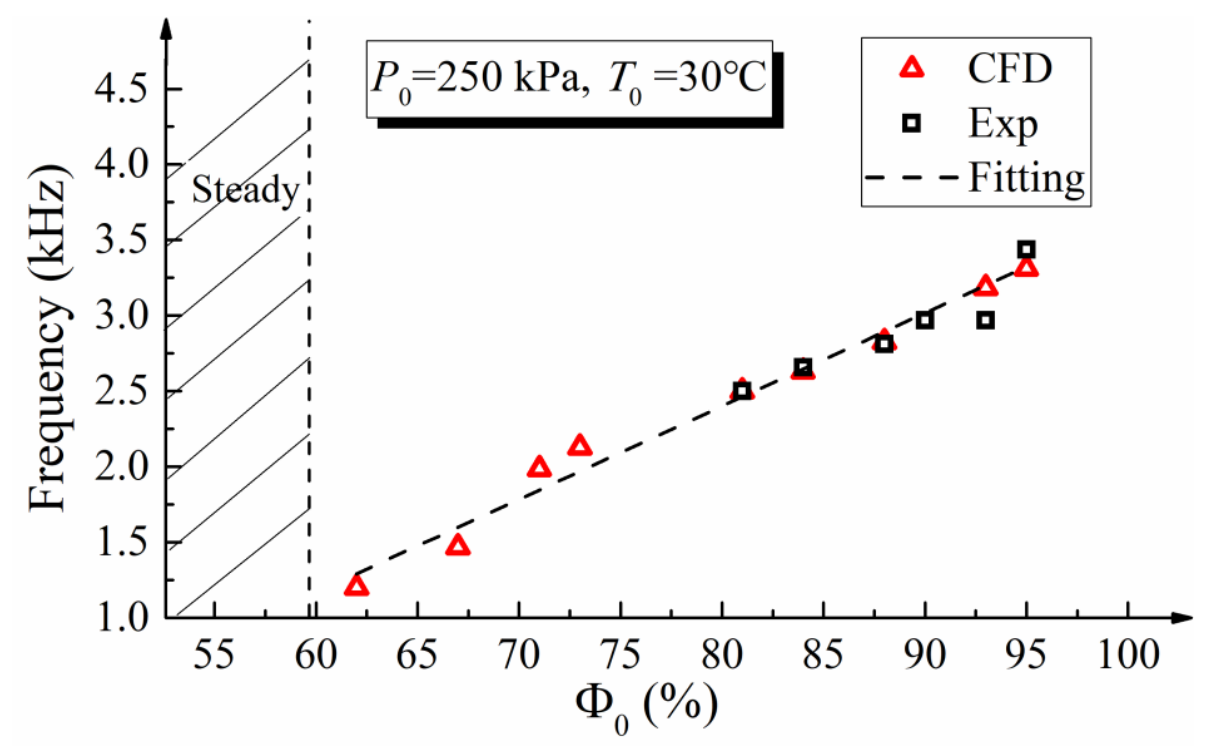

(a) Frequency changes with $\Phi_{0}$ 


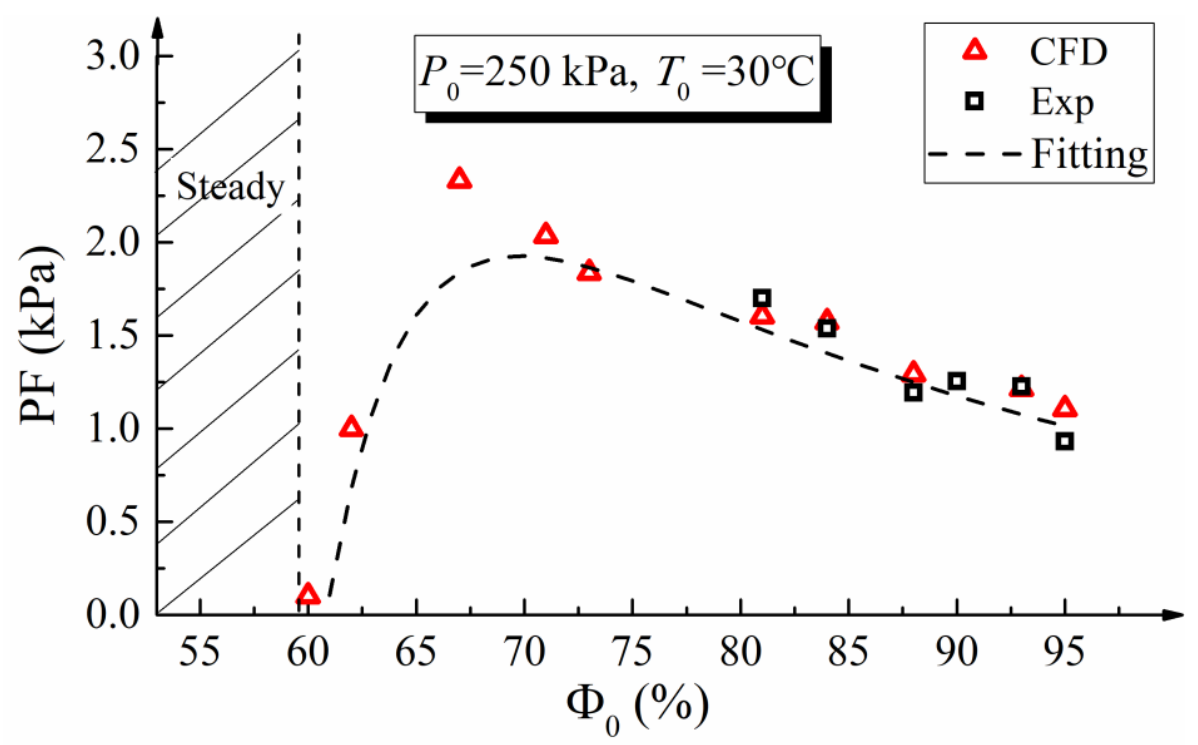

(b) PF changes with $\Phi_{0}$

Fig 10 Frequency and PF changes with different inlet humidity $\Phi_{0}$.

At $P_{0}=360 \mathrm{kPa}$ and $\Phi_{0}=87 \%$, as shown in Fig 11, the temperature limit for unsteady flow is 22 ${ }^{\circ} \mathrm{C}$. With temperature increasing, the frequency also increases, especially at the lower temperature region. The intensity value $\mathrm{PF}$ in the whole temperature range is changing, which is closed to zero at low temperature and keeps rising when temperature is higher. For the flow with the same Mach number, it is easier to reach the critical heat addition at high temperature condition. Thus, more released heat leads to a high-frequency oscillation. Due to the effect of temperature on condensation position is less than humidity, the frequency changes more gently with temperature increasing.

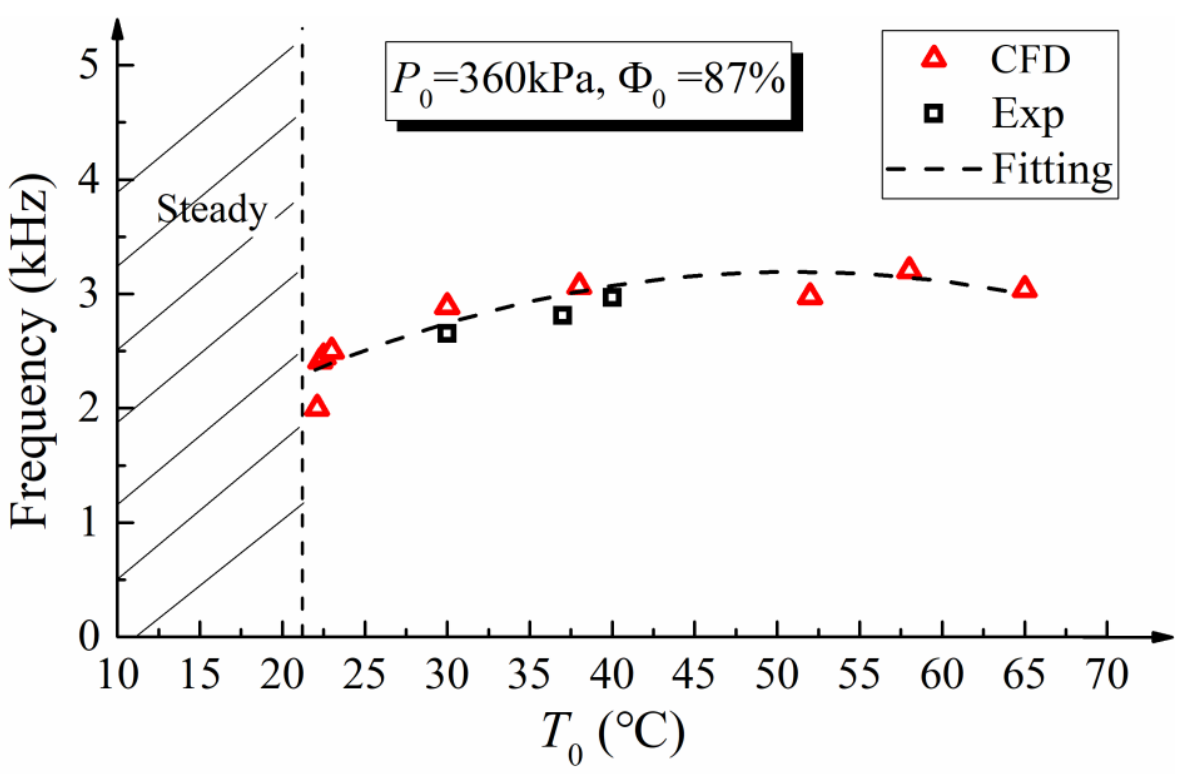

(a) Frequency changes with $T_{0}$ 


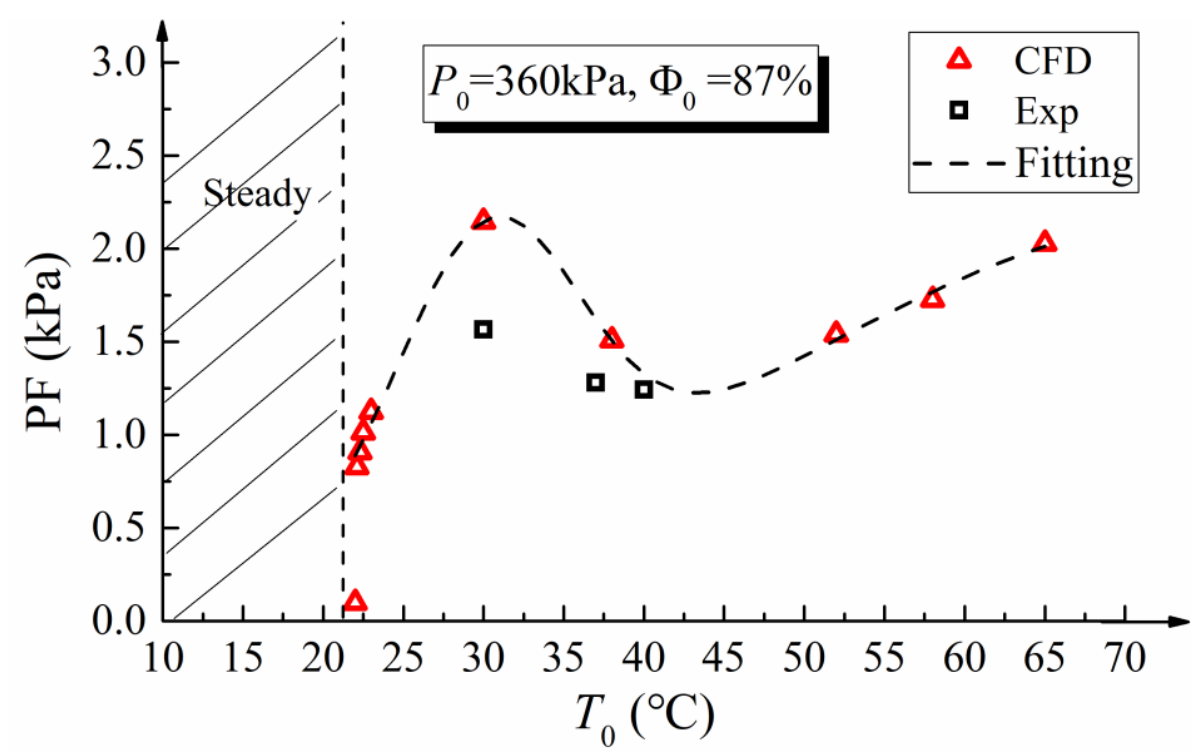

(b) PF changes with $T_{0}$

Fig 11 Frequency and PF changes with different inlet temperature $T_{0}$.

As shown in Fig 12, when $T_{0}=40{ }^{\circ} \mathrm{C}$ and $\Phi_{0}=81 \%$, the unsteady flow occurs at $P_{0} \leq 620 \mathrm{kPa}$. With inlet carrier gas pressure increasing, both frequency and intensity PF of the pressure signal increase at first and then go down at high pressure. When the pressure is low, the released speed of the latent heat increases with the carrier gas pressure increasing. Thus, the frequency increases while the intensity enhances. In high-pressure region, the released speed is constant but the critical heat addition continues to increase rapidly leading to a weaker oscillation flow with lower frequency and intensity. The unsteady flow will switch to the stable state with inlet pressure further increasing.

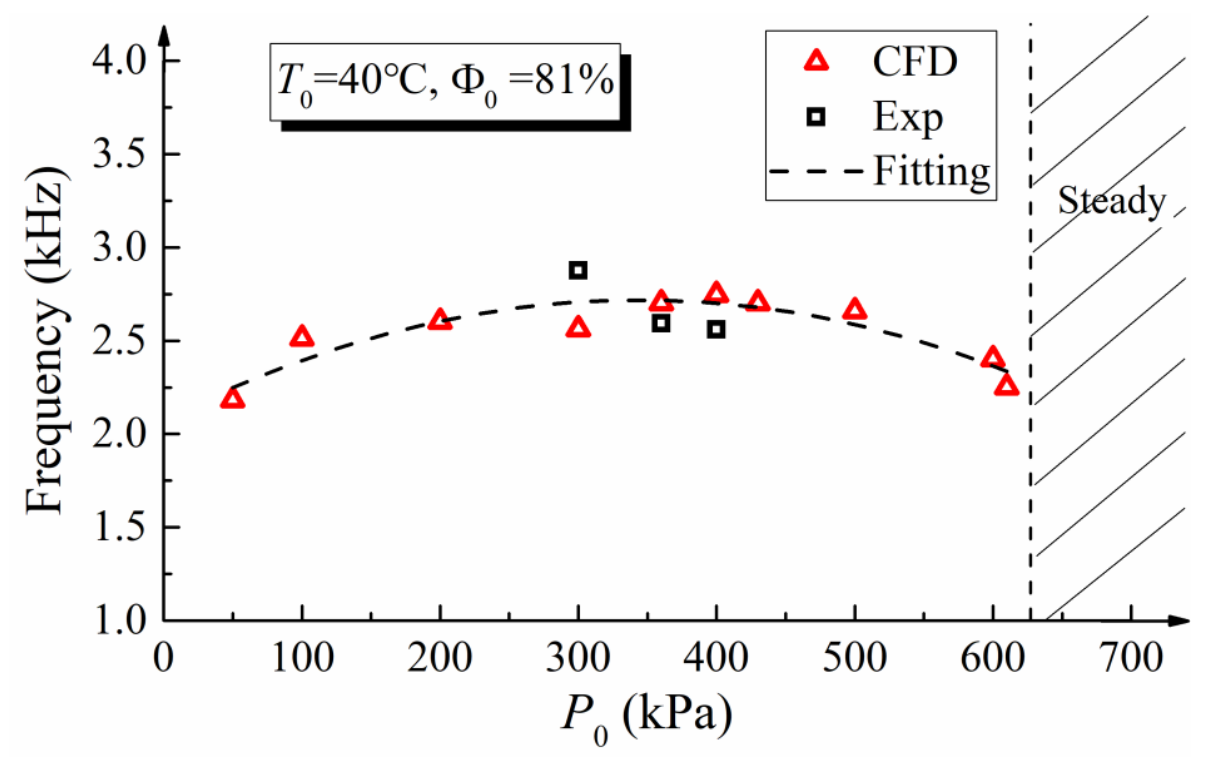

(a) Frequency changes with $P_{0}$ 


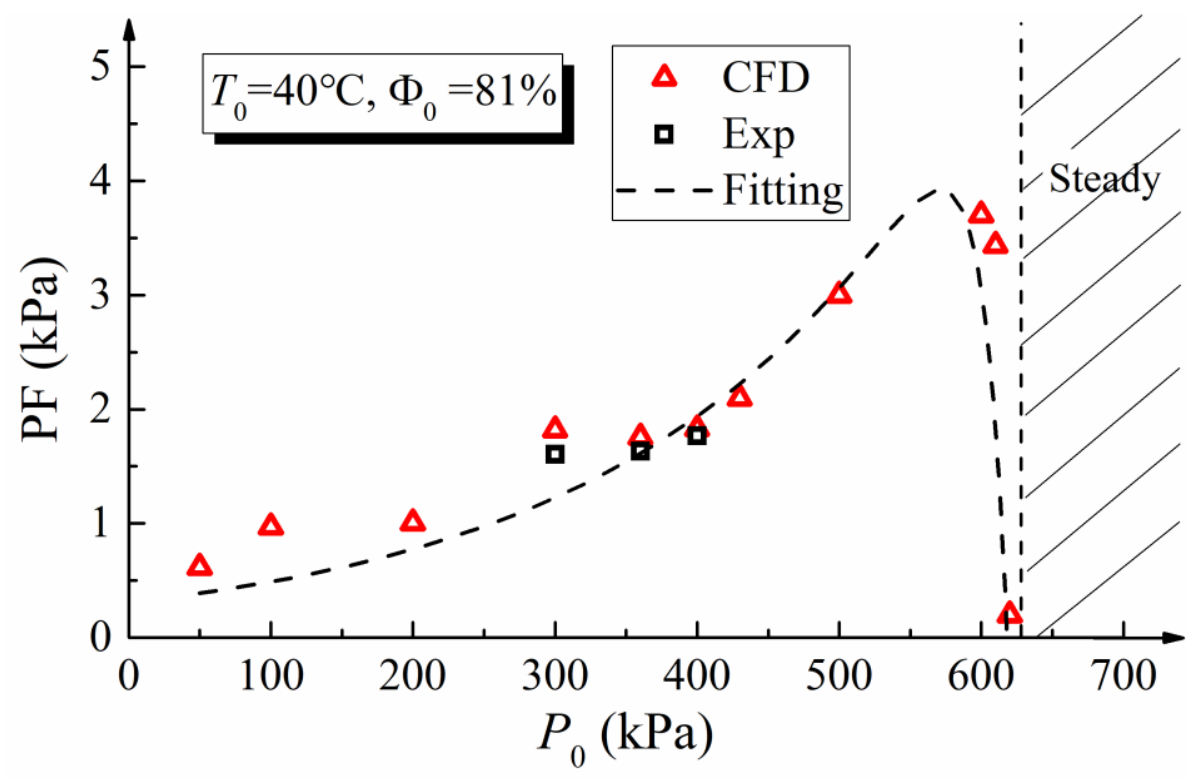

(b) PF changes with $P_{0}$

Fig 12 Frequency and PF changes with different inlet carrier gas pressure $P_{0}$.

The ranges of humidity, temperature and carrier gas pressure are listed in Table 4 . The frequency $f$ and intensity PF obtained under these conditions are also listed in it.

Table 4 The ranges of inlet conditions, $f$ and PF

\begin{tabular}{cccc}
\hline & $P_{0}=250 \mathrm{kPa}, \mathrm{T}_{0}=30^{\circ} \mathrm{C}$ & $P_{0}=360 \mathrm{kPa}, \Phi_{0}=87 \%$ & $\mathrm{~T}_{0}=40^{\circ} \mathrm{C}, \Phi_{0}=81 \%$ \\
\hline & $\Phi_{0}=60 \% \sim 95 \%$ & $T_{0}=22{ }^{\circ} \mathrm{C} \sim 65^{\circ} \mathrm{C}$ & $P_{0}=50 \mathrm{kPa} \sim 620 \mathrm{kPa}$ \\
$f$ & $1.2 \mathrm{kHz} \sim 3.4 \mathrm{kHz}$ & $2.0 \mathrm{kHz} \sim 3.2 \mathrm{kHz}$ & $2.2 \mathrm{kHz} \sim 2.9 \mathrm{kHz}$ \\
$\mathrm{PF}$ & $0.1 \mathrm{kPa} \sim 2.3 \mathrm{kPa}$ & $0.1 \mathrm{kPa} \sim 2.1 \mathrm{kPa}$ & $0.6 \mathrm{kPa} \sim 3.7 \mathrm{kPa}$ \\
\hline
\end{tabular}

The values of dimensionless frequency $f^{0}$ under the experiment conditions are calculated by semiempirical Eq. (2), as shown in Fig 13 (a), where the line denotes that the predicted result is equal to the experimental result. The results of Eq. (2) deviate from the experiment results seriously. The maximum error is $60 \%$, indicating the semi-empirical Eq. (2) has poor predictability when applying to threedimensional nozzle in this experiment. Thus, it is necessary to deduce a new semi-empirical equation. 


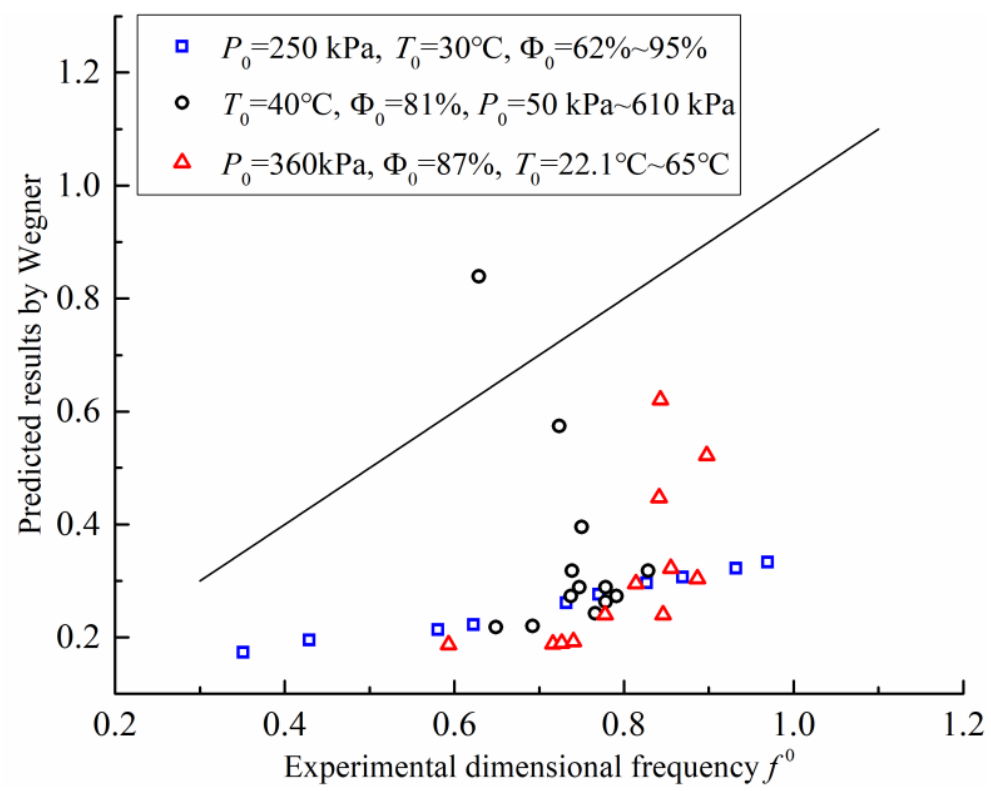

(a) The results by Wegner

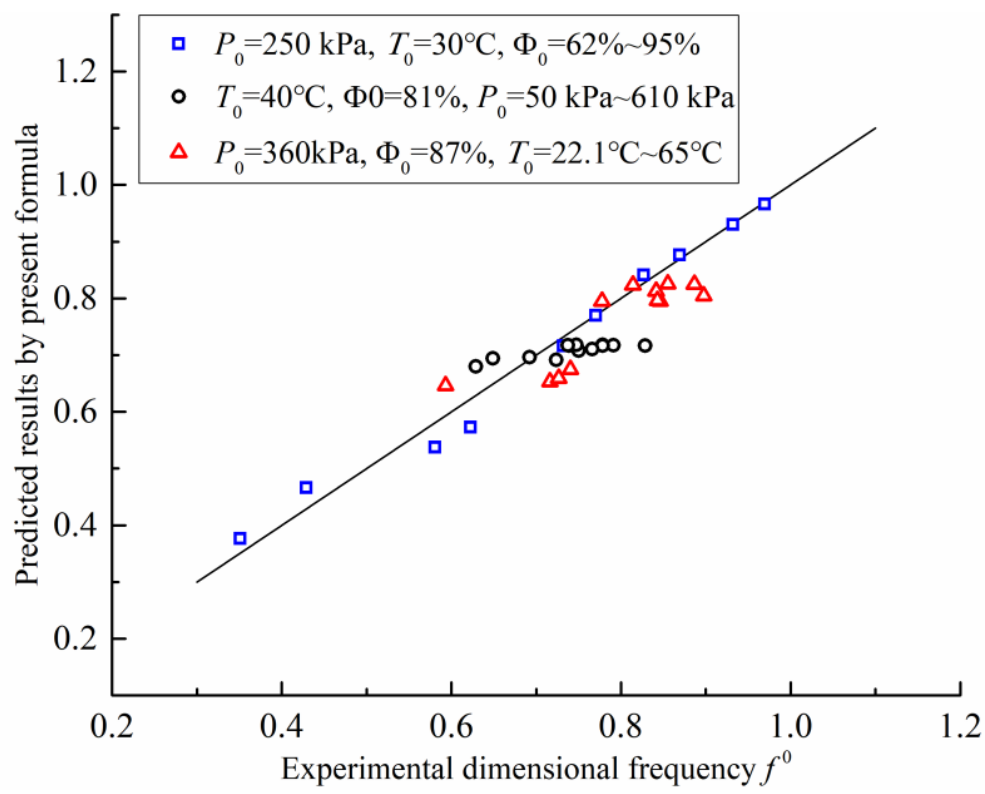

(b) The results by present formula

Fig 13 Comparison of the dimensional frequency $f^{0}$ between experimental and predicted values.

Reduced by Buckingham's theorem, the dimensionless frequency $f^{0}$ can be obtained from the frequency of the unsteady flow $f$ [33], as shown in Eq. (13), where $l$ is the characteristic nozzle length and $l=\left(R^{*} h^{*}\right)^{1 / 2}, R^{*}$ is the throat radius of curvature, $h^{*}$ is the throat diameter, $L$ is the latent heat of condensation and $\tau_{c}$ is the characteristic time at condensation condition. The subscript $v$ denotes vapor and $\infty$ denotes referring to flat surface of liquid.

$$
f^{0} \equiv \frac{f l}{a_{c r}}=G_{2}\left(\frac{P_{v 0}}{P_{\infty 0}}, \frac{P_{v 0}}{P_{0}}, \frac{L}{c_{p} T_{0}}, \frac{h^{*}}{l}, \frac{\tau_{c} a^{*}}{l}, \gamma\right)
$$


The first two terms $P_{v 0} / P_{\infty 0}$ and $P_{v 0} / P_{0}$ are respectively proportional to the inlet relative humidity $\Phi_{0}$ and mass fraction of water vapor $w_{0}$. Moreover, $w_{0}$ is a function of $\Phi_{0}$, as shown in Eq. (14), where $w_{s}$ is the saturated mass fraction of water vapor.

$$
w_{0}=F\left(\Phi_{0}, w_{s}\right)
$$

In order to make the variables independent of each other, $w_{s}$ is chosen as the dependent variable. Thus, $f^{0}$ can be expressed as

$$
f^{0}=G_{3}\left(\Phi_{0}, w_{s}, \frac{L}{c_{p} T_{0}}, \frac{h^{*}}{l}, \frac{\tau_{c} a^{*}}{l}, \gamma\right)
$$

Due to the small interval of inlet temperature, $L /\left(c_{p} T_{0}\right)$ is regarded as a constant. For fixed $\gamma$ and small range of nozzle geometries $h^{*} / l, \tau_{c} a^{*} / l$ is expected to show little variation. Finally, a simple semi-empirical function can be obtained, as shown in Eq. (16).

$$
f^{0}=G_{4}\left(\Phi_{0}, w_{s}\right)
$$

Based on above results of experiment and mathematical model, the final identified semi-empirical equation is

$$
f^{0}=a_{0}\left(b_{1} \Phi_{0}+b_{0}\right)\left(c_{2} w_{s}^{-2}+c_{1} w_{s}^{-1}+c_{0}\right)
$$

where $a_{0}=1.32, b_{1}=1.79, b_{0}=-0.73, c_{2}=-8.58 \times 10^{-6}, c_{1}=0.0013, c_{0}=0.70$.

The predicted result of Eq. (17) is plotted in Fig 13 (b), in which the scatters are distributed near the line. The average error of Eq. (17) is $5.51 \%$, the maximum error is $13.53 \%$, the sum of squares error is 0.08 and R-square is 0.86 . It is indicated that the error is reduced significantly compared with the semi-empirical equation of Wegner.

\section{Nonstationarity of Pressure Fluctuation}

To analyze the nonstationarity of pressure fluctuation, two pressure fluctuation signals with typical nonstationary characteristic were chosen and compared to illustrate the signal features. The experiment conditions are as follows: for Signal $1, P_{0}=360 \mathrm{kPa}, T_{0}=40{ }^{\circ} \mathrm{C}$ and $\Phi_{0}=85 \%$; for Signal 2, $P_{0}=300 \mathrm{kPa}, T_{0}=25^{\circ} \mathrm{C}$ and $\Phi_{0}=88 \%$.

The characteristic of time series reconstructed by DWT is analyzed preliminarily. In time domain, probability density function (PDF) of the pressure increment $\Delta P(t, \Delta t)=P(t+\Delta t)-P(t)$ is used to reflect the probability distribution of the pressure changing rate.

Fig 14 shows the PDF of pressure increment $\Delta P$ for time delay $\Delta t=5 \mathrm{~ms}$. Compared with Signal 2, the shape of Signal 1 is wider and shorter. The ranges of $\Delta P$ are $-10 \sim 10 \mathrm{kPa}$ and $-5 \sim 5 \mathrm{kPa}$ respectively for the two signals. The $\Delta P$ values are dispersed in Signal 1 while concentrate in a smaller range in Signal 2. It is illustrated that there are more drastic changes in Signal 1. 


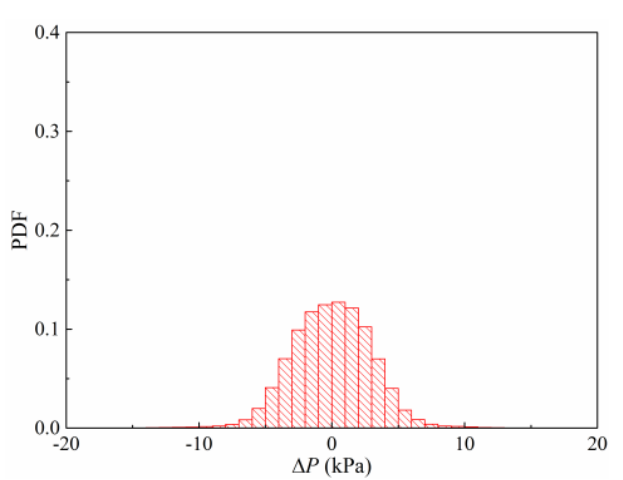

(a) PDF of Signal 1

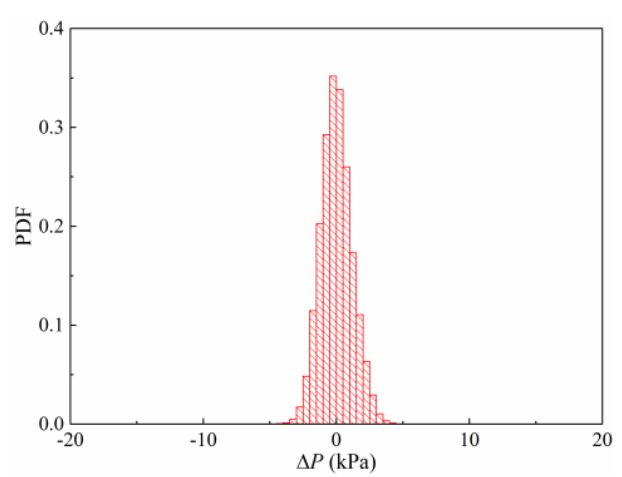

(b) PDF of Signal 2

Fig $14 \mathrm{PDF}$ of pressure increments corresponding to the two typical signals ( $\Delta t=5 \mathrm{~ms}$ ).

Since the pressure fluctuation signals contain several frequency components, the flatness FF of A8, D8-D1 corresponding to different frequency ranges are calculated by Eq. (11). The results of Signal 1 and 2 are shown in Table 5. For Gaussian distribution, the value of FF is 3 [53]. For intermittent systems, the flatness can also be seen as the ratio of time spent under quiescent conditions to the time spent under active conditions. The value of FF increases with frequency increasing, indicating that high frequency components of these two signals are more intermittent. Especially for the value of D3 and D4, Signal 1 with higher FF is more intermittent than Signal 2.

Table 5 FF of Signal 1 and Signal 2.

\begin{tabular}{cccccccccc}
\hline FF & A8 & D8 & D7 & D6 & D5 & D4 & D3 & D2 & D1 \\
\hline Signal 1 & 3.0121 & 3.7687 & 6.0856 & 7.2264 & 18.6429 & 32.5588 & 24.9255 & 43.9808 & 104.7524 \\
Signal 2 & 1.8777 & 3.5246 & 3.4022 & 3.5750 & 4.2362 & 2.4585 & 3.5130 & 6.6344 & 39.3718 \\
\hline
\end{tabular}

In order to characterize the nonstationary signal on its local frequency properties in detail, Signal 1 and 2 are transformed into time-frequency domain by CWT. The complex Morlet wavelet was chosen as the mother wavelet. As shown in Fig 15 (a) and (c), there are the LWE map derived from CWT coefficients for Signal 1 and 2, which are calculated by Eq. (12). The estimated scale is located within the range of 1000-1300, namely frequency range is 1000-5000 Hz. In the LWE map, the dark color represents greater LWE modulus, while the light color means smaller absolute values. Quantitatively, wavelet ridge in above frequency range is extracted to show the instantaneous frequency of the signal, as shown in Fig 15 (c) and (d). 


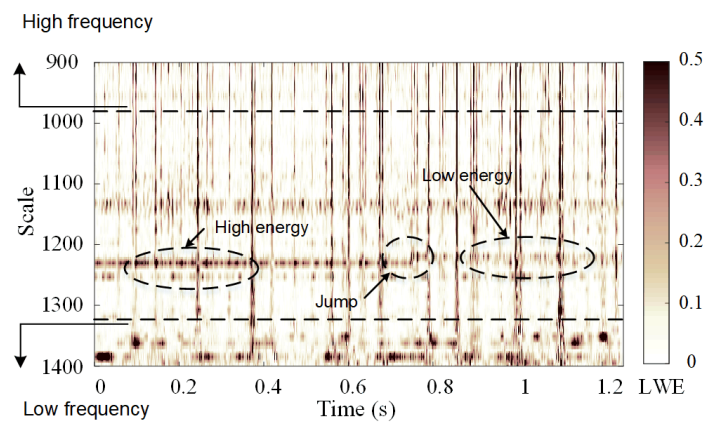

(a) LWE map of Signal 1

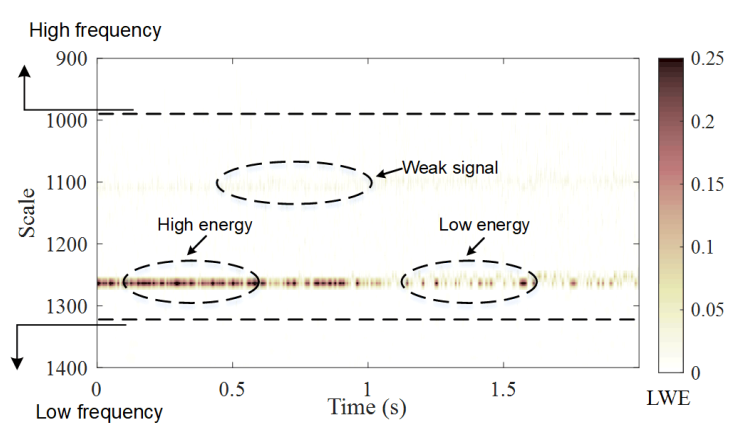

(c) LWE map of Signal 2

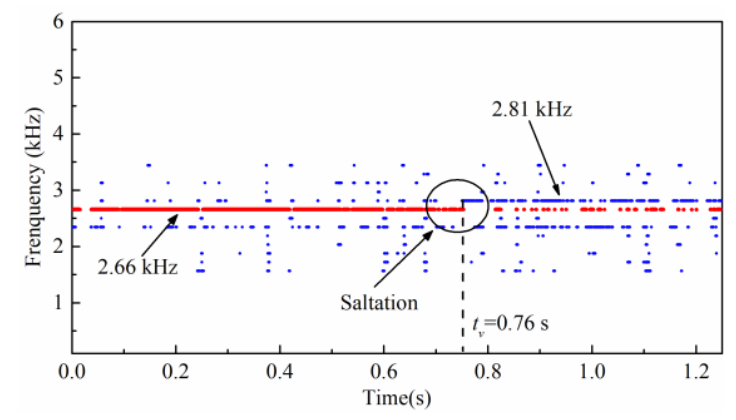

(b) Wavelet ridge of Signal 1

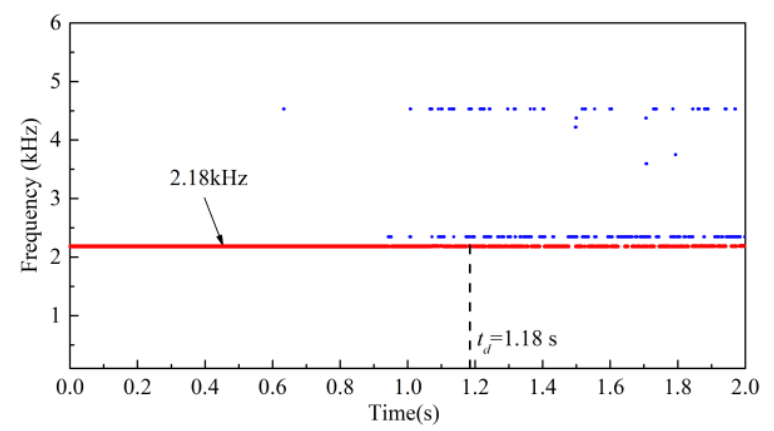

(d) Wavelet ridge of Signal 2

Fig 15 The result of CWT for Signal 1 and 2.

From the result of Signal 1 (Fig 15 (a) and (b)), it is found that on the larger scale which is corresponding to lower frequency, there are dark areas occur alternately. Several dark lines occur occasionally with time. In the scale range of 1200-1300, there is a dark band corresponding to the frequency of $2.66 \mathrm{kHz}$ in Fig 15 (b). At $t_{v}=0.76 \mathrm{~s}$, there occurs a frequency saltation from $2.66 \mathrm{kHz}$ to $2.81 \mathrm{kHz}$. After the saltation, the energy of the frequency of $2.66 \mathrm{kHz}$ becomes weak. Meanwhile, there are also some signals with high frequency but weak energy. The LWE map of Signal 2, shown in Fig 15 (c), is clearer than that of Signal 1. There is a clear dark band corresponding to frequency of 2.18 $\mathrm{kHz}$. But the color becomes light obviously after time of $t_{d}=1.18 \mathrm{~s}$, meaning its energy attenuates.

For frequency of $2.66 \mathrm{kHz}$ and $2.18 \mathrm{kHz}$ respectively of Signal 1 and 2, the LWE coefficients are extracted and shown in Fig 16, it can be seen that the coefficients decrease at $t_{v}=0.76 \mathrm{~s}$ and $t_{d}=1.18 \mathrm{~s}$. By contrast, the coefficients of Signal 1 are larger than that of Signal 2 because of its higher energy. And there are more changes in Signal 1. Additionally, the specific information of wavelet ridge are listed in Table 6, where $t_{c}$ is the time when the signal occurs a sudden change including frequency saltation for Signal 1 and energy attenuation for Signal 2. 


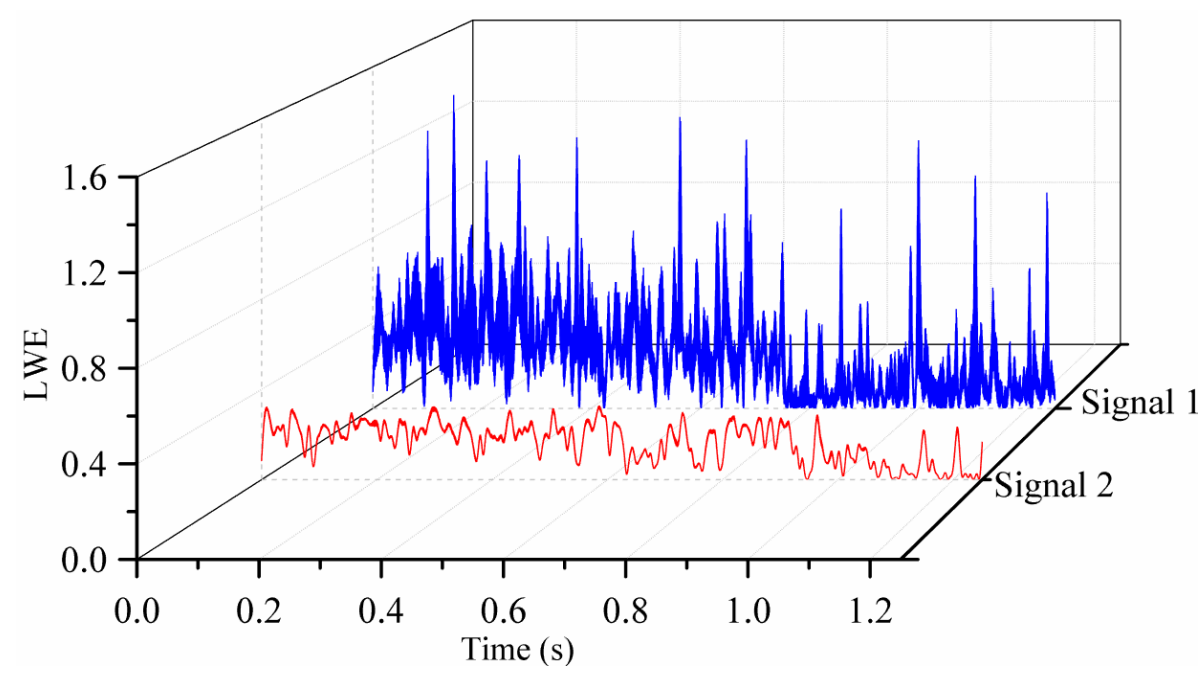

Fig 16 LWE coefficients of wavelet ridge for Signal 1 and 2.

Table 6 The information of wavelet ridge for Signal 1 and Signal 2

\begin{tabular}{ccccc}
\hline & Frequency feature & $t_{c}$ & Average of LWE & Variance of LWE \\
\hline Signal 1 & from 2.66 kHz to 2.81 kHz & $0.76 \mathrm{~s}$ & 0.2629 & 0.0404 \\
Signal 2 & $2.18 \mathrm{kHz}$ & $1.18 \mathrm{~s}$ & 0.1652 & 0.0071 \\
\hline
\end{tabular}

It is shown that the pressure fluctuation signals probably are nonstationary, both its frequency and intensity. Besides, the nonstationary features extracted from CWT are match up with the results of PDF and FF in the previous subsection. Compared with Signal 2, Signal 1 is more intermittent. These results are benefit for analyzing the effects of humidity, temperature and carrier gas pressure on the vapor condensation of moist air in a sonic nozzle and guiding the sonic nozzle design and mass flow-rate measurement.

\section{CONCLUSION}

The non-equilibrium condensation of moist air in the sonic nozzle were investigated combining a series of experiments and physical simulation. The results indicated that along with $\Phi_{0}$ increasing, the frequency of pressure fluctuation increases, while the intensity PF increases rapidly at first and then goes down generally. The frequency increases with $T_{0}$ increasing and the intensity PF is closed to zero at low temperature and keeps rising when temperature is higher. With $P_{0}$ increasing, both frequency and intensity PF increase at first and then go down. The new semi-empirical relation of dimensionless frequency at various conditions is $f^{0}=1.32\left(1.79 \Phi_{0}-0.73\right)\left(-8.58 \times 10^{-6} w_{s}^{-2}+0.0013 w_{s}^{-1}+0.70\right)$ and the average error is reduced to $5.51 \%$. The signal nonstationarity was also observed by using CWT. For the typical nonstationary Signal 1, it occurs a frequency saltation from $2.66 \mathrm{kHz}$ to $2.81 \mathrm{kHz}$ at $0.76 \mathrm{~s}$. For Signal 2, its energy attenuates after $1.18 \mathrm{~s}$. The results above are useful in assessing the effect of vapor condensation on the accuracy and stability of mass flow rate of the sonic nozzle.

\section{ACKNOWLEDGEMENTS}

This work is supported by National Natural Science Foundation of China under Grant 51876143, 61873184, and 61627803, Natural Science Foundation of Tianjin under Grant 16JCQNJC03700 and 
18JCQNJC74500, European Union's Horizon 2020 research and innovation programme under the Marie Sklodowska Curie grant agreement No. 792876.

\section{REFERENCE}

[1]. H. Ding, C. Wang, Y. Zhao, "Surface roughness effect on flow measurement of real gas in a critical nozzle," Measurement, vol. 68 , pp. 82-91, 2015.

[2]. C. Wang, H.B. Ding, and H.X. Wang, "Thermodynamic model and dynamic temperature compensation in positivepressure-based sonic nozzle gas flow standard”, IEEE Trans. Instrum. Meas, vol. 62, pp. 1154-1165, 2013.

[3]. C. Li, B. Mickan, "The humidity effect on the calibration of discharge coefficient of sonic nozzle by means of pVTt facility", In: Proceedings of the 8th international symposium on fluid flow measurement, no. 302, Colorado, June 2012.

[4]. J. M. Lim, B. H. Yoon, Y. K. Oh, et al. "The humidity effect on air flow rates in a critical flow venture nozzle," Flow Meas. Instrum. vol. 22, pp. 402-405, 2011.

[5]. K. Chahine, M. Ballico, "Evaluation of the Effect of Relative Humidity of Air on the Coefficients of Critical Flow Venturi Nozzles," Flomeko, Paris, France, 2013.

[6]. A. Demetriades, "Cooling and roughness effects on transition on nozzle throats and blunt bodies," J. Spacecraft Rockets, vol. 29 , no. 4 , pp. 432-436, 1992.

[7]. A. Ozalp, "Numerical analysis of choked converging nozzle flows with surface roughness and heat flux conditions," Sadhana, vol. 31 no. 1, pp. 31-46, 2006.

[8]. C Wang, P. Cao, C Li, et al. "Influence of wall roughness on boundary layer transition position of the sonic nozzles," Measurement, vol. 139, pp. 196-204, 2019.

[9]. K. Park, "Effects of inlet shapes of critical venturi nozzles on discharge coefficients," vol. 6, no. 1, pp. 15-19, 1995.

[10]. J. Kim, H. Kim, T. Seoguchi, "The effect of diffuser angle on the discharge coefficient of a miniature critical nozzle," Therm. Sci. vol. 19, no. 3, pp. 222-227, 2010.

[11]. C. Li, B. Mickan, "Humidity effect on the calibration of discharge coefficients of critical flow Venturi nozzles in a pVTt facility," Flow Meas. Instrum. vol, 46, pp. 125-132, 2015.

[12]. H. Ding, C. Wang, C. Chen, "Non-equilibrium condensation process of water vapor in moist air expansion through a sonic nozzle," Flow Meas. Instrum., vol. 40, pp. 238-246, 2014.

[13]. H. Ding, C. Wang, C. Chen, "Experimental and numerical studies on self-excited periodic oscillation of vapor condensation in a sonic nozzle," Exp. Therm. Fluid Sci., vol. 68, pp. 288-299, 2015.

[14]. A.A. Pouring, "Thermal choking and condensation in nozzles,” Phys. Fluids, vol. 8, pp. 1802-1810, 1965.

[15]. C. Wang, X. Wang, H. Ding, "Boundary layer of non-equilibrium condensing steam flow in a supersonic nozzle," Appl. Therm. Eng. vol. 129, pp. 389-402, 2018.

[16]. T. Setoguchi, S. Matsuo, S. Yu, H. Hirahara, "Effect of nonequilibrium homogenous condensation on flow fields in a supersonic nozzle," J. Therm. Sci. vol. 6, no. 2, pp. 90-96, ) 1997.

[17]. S. Matsuo, T. Setoguchi, S. Yu, K. Matsuo, "Effect of nonequilibrium condensation of moist air on the boundary layer in a supersonic nozzle,” J. Therm. Sci. vol. 6, no. 4, pp. 260-272, 1997.

[18]. B. E. Wyslouzil, C. H. Heath, J. L. Cheung, et al. "Binary condensation in a supersonic nozzle," J. Chem. Physics, vol. 113, no. 17,pp. 7317-7329, 2000.

[19]. G. Lamanna, “On nucleation and droplet growth in condensing nozzle flows," PhD, thesis, Eindhoven University of Technolog, 2000 .

[20]. G. Lamanna, J. van Poppel, M. van Dongen, "Experimental determination of droplet size and density field in condensing flows," Exp. Fluids, vol. 32, pp. 381-395, 2002.

[21]. J. B. Young, “The spontaneous condensation of steam in supersonic nozzles," Phys. Chem. Hydrodyn. vol. 3, no. 1, pp. 57$82,1996$.

[22]. Q. Ma, D. Hu, J. Jiang, Z. Qiu, “A turbulent Eulerian multi-fluid model for homogeneous nucleation of water vapour in transonic flow," Int. J. Comput. Fluid Dynam., vol. 23, no. 3, pp. 221-231, 2009.

[23]. Q. Ma, D. Hu, J. Jiang, et al. "Numerical study of the spontaneous nucleation of self-rotational moist gas in a convergingdiverging nozzle," Int. J. Comput. Fluid Dynam. vol. 24, no. 1-2, pp. 29-36, 2010)

[24]. X. Lv, B. Bai, “A multi-fluid model for non-equilibrium condensation in gaseous carrier flows,” Appl. Therm. Eng. vol. 65, 
no. 1, pp. 24-33, 2014.

[25]. H. Ding, C. Wang, C. Chen, "Effect of carrier gas pressure on vapor condensation and mass flow-rate in sonic nozzle," $J$. Central South Univ. vol. 22, no. 12, pp. 4864-4871, 2015.

[26]. S. Hamidi, M. J. Kermani, "Numerical study of non-equilibrium condensation and shock waves in transonic moist-air and steam flows,” Aero. Sci. Tech. vol. 46, pp. 188-196, 2015.

[27]. F. Bakhtar, M. T. Mohammadi, "An investigation of two-dimensional flows of nucleating and wet steam by the timemarching method," Int. J. Heat Fluid Flow vol. 2, no. 1, pp. 5-18, 1980.

[28]. J. B. Young, "Two-dimensional, nonequilibrium, wet-steam calculations for nozzles and turbine cascades,"J. Turbo., vol. 114, no. 3, pp. 569-579, 1992.

[29]. J. Halama, V. Hric, "Numerical solution of steam flow in a nozzle using different non-equilibrium condensation models," Appl. Math. Comput., vol. 272, pp. 657-669, 2016.

[30]. J. H. Chang, I. K. Park, et al. "Numerical analysis of non-equilibrium steam condensing flows in various Laval nozzles and cascades,” Eng. Appl. Comput. Fluid Mech., vol. 11, no. 1, pp. 172-183, 2017.

[31]. E. Jabir, et al. "Numerical estimation of non-equilibrium condensation of steam in supersonic nozzles," J. Mech. Sci. Tech., vol. 32, no. 10, pp. 4649-4655, 2018.

[32]. H. Ding, Y. Li, E. Lakzian, et al. "Entropy generation and exergy destruction in condensing steam flow through turbine blade with surface roughness," Energ. Convers. Manage. vol. 196, pp. 1089-1104, 2019.

[33]. P. P. Wegener, D. J. Cagliostro, "Periodic nozzle flow with heat addition," Combust. Sci. Tech., vol. 6, no. 5, pp. 269-277, 1973.

[34]. P. P. Wegener, F. Mosnier, "Periodic transonic flow with heat addition: new results," Combust. Sci. Tech., vol. 24, no. 5-6, pp. 179-189, 1981

[35]. K. Matsuo, S. Kawagoe, K. Sonoda, T. Setoguchi, "Oscillations of laval nozzle flow with condensation: part 1, on the range of oscillations and their frequencies," Bulletin of the JSME, vol. 26, no. 219, pp. 1556-1562, 1983.

[36]. W. Frank, "Condensation phenomena in supersonic nozzles," Acta Mech., vol. 54, no. 3-4, pp. 135-156, 1985.

[37]. S.A. Skillings, P.T. Walters, M.J. Moore, "A study of supercritical heat addition as a potential loss mechanism in condensing steam turbines," J. Mech. Eng. Sci., vol. 259, no. 87, pp. 125-134, 1987.

[38]. S. Adam, G. Schnerr, I"nstabilities and bifurcation of non-equilibrium two-phase flows," J. Fluid Mech., vol. 348, pp. 1-28, 1997.

[39]. N. A. Malek, H. Hasini, and M. Z. Yusoff, "One-dimensional analysis of unsteady flows due to supercritical heat addition in high speed condensing steam,” IOP Conf. Series: Earth Environ. Sci., vol. 16, pp. 012150, 2013.

[40]. X. Yu, D. Xie, C. Wang, et al. "Numerical investigation of oscillating flows with nonequilibrium condensation in nozzles," J. Propul. Power, vol. 31, no. 3, pp. 837-842, 2015.

[41]. H. Ding, Y Li, J Li, et al. "Feature extraction based on optimal Morlet wavelet for the pressure oscillation induce by vapor condensation in a sonic nozzle," in Proc. Instrum. Meas. Technol. Conf., Auckland, New Zealand, 2019, pp. 1-5.

[42]. P. P. Wegener, A. A. "Pouring, Experiments on Condensation of Water Vapor by Homogeneous Nucleation in Nozzles," Physics of Fluids, vol. 7, no. 3, pp. 352, 1964.

[43]. H. Ding, C. Wang, C. Chen, "Non-equilibrium condensation of water vapor in sonic nozzle," Appl. Therm. Eng., vol. 71, no. 1, pp. 324-334, 2014.

[44]. H. Bergh, H. Tijdeman, "Theoretical and experimental results of dynamic response of pressure measuring system," Report NLR-TRF, vol. 97, no. 1, pp. 217-224, 1965.

[45]. H. Kage, M. Agari, H. Ogura, et al. "Frequency analysis of pressure fluctuation in fluidized bed plenum and its confidence limit for detection of various modes of fluidization," Adv. Powder Technol., vol. 11, no. 4, pp. 459-475, 2000.

[46]. C. Tan, P. Li, W. Dai, et al. "Characterization of oil - water two-phase pipe flow with a combined conductivity/capacitance sensor and wavelet analysis," Chem. Eng. Sci., vol. 134, pp. 153-168, 2015.

[47]. H. Li, X. Chen, Q. Ouyang, et al. "Wavelet analysis on fluctuating characteristics of airflow in building environments," Build. Environ. vol. 42, no. 12, pp. 4028-4033, 2007.

[48]. F. Johnsson, R. C. Zijerveld, J. C. Schouten, et al. "Characterization of fluidization regimes by time-series analysis of pressure fluctuations," Int. J. Multiph. Flow, vol. 26, no. 4, pp. 663-715, 2000.

[49]. J.Sun. "Research on gas-solid fluidized bed flow field properties and flow structure based on particle pulsation parameter CFD simulation," Zhejiang University, 2013. 
[50]. J. Slavič, I. Simonovski, M. Boltežar, "Damping identification using a continuous wavelet transform: Application to real data," J. Sound Vib., vol. 262, no. 2, pp. 291-307, 2003.

[51]. J. R. V. Ommen, S. Sasic, J. V. D. Schaaf, et al. "Time-series analysis of pressure fluctuations in gas - solid fluidized beds A review," Int. J. Multiph. Flow, vol. 37, no. 5, pp. 403-428, 2011.

[52]. H. Ding, C. Wang, G. Wang, "Self-excited oscillation of non-equilibrium condensation in critical flow nozzle," Appl. Therm. Eng., vol. 122, pp. 515-527, 2017.

[53]. H. S. Greenside, G. Ahlers, P.C. Hohenberg, R. W. Walden, "A simple stochastic model for the onset of turbulence in Rayleigh-Benard convection,” Physica D., vol. 5, no. 2, pp. 322-334, 1982. 


\section{List OF FiguRE CAPTIONS AND TABLE TITLES}

Fig 1 Typical condensation zones in sonic nozzle and pressure changes. (a) Nozzle structure and condensation zones (b) Pressure changes in condensing and frozen flows

Fig 2 The adjustable humidification apparatus. (a) Schematic and photograph of the apparatus (b) The $3 \mathrm{D}$ toroidal-throat sonic nozzle

Fig 3 The micro-size pressure measuring system. (a) Pressure probe array (b) Kulite MEMS quickly response pressure probe

Fig 4 Structure of the pressure measuring system.

Fig 5 The amplitude-frequency characteristic curve of pressure measuring system.

Fig 6 Pressure distribution and latent heat addition rate with humidity changing. (a) $P / P_{0}$ with $P_{0}=300$ $\mathrm{kPa}, T_{0}=50^{\circ} \mathrm{C}$ (b) $q_{l}$ with $P_{0}=300 \mathrm{kPa}, T_{0}=50{ }^{\circ} \mathrm{C}$ (c) $P / P_{0}$ with $P_{0}=400 \mathrm{kPa}, T_{0}=50{ }^{\circ} \mathrm{C}$ (d) $q_{l}$ with $P_{0}$ $=400 \mathrm{kPa}, T_{0}=50^{\circ} \mathrm{C}$

Fig 7 Pressure distribution with temperature changing. (a) with $P_{0}=300 \mathrm{kPa}, \Phi_{0}=80 \%$ (b) with $P_{0}=$ $500 \mathrm{kPa}, \Phi_{0}=80 \%$

Fig 8 Pressure distribution with pressure changing. (a) with $T_{0}=50{ }^{\circ} \mathrm{C}, \Phi_{0}=80 \%$ (b) with $T_{0}=30{ }^{\circ} \mathrm{C}$, $\Phi_{0}=95 \%$

Fig 9 Signal in time and frequency domain. (a) Signal in time domain (b) Signal in frequency domain Fig 10 Frequency and PF changes with different inlet humidity $\Phi 0$. (a) Frequency changes with $\Phi_{0}$ (b) PF changes with $\Phi_{0}$

Fig 11 Frequency and PF changes with different inlet temperature TO. (a) Frequency changes with $T_{0}$ (b) PF changes with $T_{0}$

Fig 12 Frequency and PF changes with different inlet carrier gas pressure $P 0$. (a) Frequency changes with $P_{0}$ (b) PF changes with $P_{0}$.

Fig 13 Comparison of the dimensional frequency $f^{0}$ between experimental and predicted values. (a) The results by Wegner (b) The results by present formula

Fig 14 PDF of pressure increments corresponding to the two typical signals ( $\Delta \mathrm{t}=5 \mathrm{~ms}$ ). (a) PDF of Signal 1 (b) PDF of Signal 2.

Fig 15 The result of CWT for Signal 1 and 2. (a) LWE map of Signal 1 (b) Wavelet ridge of Signal 1 (c) LWE map of Signal 2 (d) Wavelet ridge of Signal 2

Fig 16 LWE coefficients of wavelet ridge for Signal 1 and 2.

Table 1 Instruments used for measurements in the adjustable humidification apparatus

Table 2 The hole locations in nozzle.

Table 3 Pressure jump position $x p$ and quantity $\Delta \mathrm{Pj}$ under different conditions.

Table 4 The ranges of inlet conditions, $f$ and $\mathrm{PF}$

Table 5 FF of Signal 1 and Signal 2.

Table 6 The information of wavelet ridge for Signal 1 and Signal 2 